Published in final edited form as:

Biochim Biophys Acta Gen Subj. 2018 October ; 1862(10): 2191-2203. doi:10.1016/j.bbagen.

2018.07.002.

\title{
Ablation of $\mathrm{N}$-acetylglucosaminyltransferases in Caenorhabditis induces expression of unusual intersected and bisected $\mathrm{N}$ - glycans
}

\author{
Shi Yan (间石) $)^{1,2}$, Huijie Wang (王彗捷) ${ }^{1}$, Harry Schachter ${ }^{3}$, Chunsheng Jin (金春生) ${ }^{4}$, lain B. \\ H. Wilson ${ }^{1, *}$, and Katharina Paschinger ${ }^{1}$ \\ ${ }^{1}$ Department für Chemie, Universität für Bodenkultur, 1190 Wien, Austria \\ 2Institut für Parasitologie, Veterinärmedizinische Universität Wien, 1210 Wien, Austria \\ ${ }^{3}$ Hospital for Sick Children and University of Toronto, Toronto, ON M5G 1X8, Canada \\ ${ }^{4}$ Institutionen för Biomedicin, Göteborgs universitet, 40530 Göteborg, Sweden
}

\section{Abstract}

The modification in the Golgi of $\mathrm{N}$-glycans by $N$-acetylglucosaminyltransferase I (GlcNAc-TI, MGAT1) can be considered to be a hallmark of multicellular eukaryotes as it is found in all metazoans and plants, but rarely in unicellular organisms. The enzyme is key for the normal processing of $\mathrm{N}$-glycans to either complex or paucimannosidic forms, both of which are found in the model nematode Caenorhabditis elegans. Unusually, this organism has three different GlcNAcTI genes ( $g l y-12, g l y-13$ and $g l y-14)$; therefore, a complete abolition of GlcNAc-TI activity required the generation of a triple knock-out strain. Previously, the compositions of N-glycans from this mutant were described, but no detailed structures. Using an off-line HPLC-MALDITOF-MS approach combined with exoglycosidase digestions and MS/MS, we reveal that the multiple hexose residues of the N-glycans of the $g l y-12 ; g l y-13 ; g l y-14$ triple mutant are not just mannose, but include galactoses in three different positions ( $\beta$-intersecting, $\beta$-bisecting and $\alpha$ terminal) on isomeric forms of $\mathrm{Hex}_{4-8} \mathrm{HexNAc}_{2}$ structures; some of these structures are fucosylated and/or methylated. Thus, the N-glycomic repertoire of Caenorhabditis is even wider than expected and exhibits a large degree of plasticity even in the absence of key glycan processing enzymes from the Golgi apparatus.

\section{Introduction}

$\mathrm{N}$-glycans probably represent the most diverse range of post-translational modifications of proteins, whereby the linkage of oligosaccharides to asparagine residues is known in many bacteria or archaea and in almost all eukaryotes (1). The heterogeneity of N-glycan structures in most eukaryotes is due to processing events in the Golgi apparatus. In multicellular organisms, three glucose and up to four a 1,2-mannose residues are removed prior to the 'rebuilding' of the oligosaccharide by glycosyltransferases; a key enzyme, thereby, is $N$-acetylglucosaminyltransferase I (GlcNAc-TI, EC 2.4.1.101, encoded in

\footnotetext{
*To whom correspondence should be addressed: iain.wilson@boku.ac.at.
} 
mammals by mgat1 genes), which appears to be absent from most unicellular eukaryotes (2). The biological phenotypes caused by ablation of mgat 1 genes vary from altered susceptibility to stress in plants or to bacteria in Caenorhabditis elegans through to cell migration or neuronal defects in invertebrates and, most severely, embryonic lethality in mice (3-8). The glycomic changes in mgat1 mutants are always significant, as $\mathrm{Man}_{5} \mathrm{GlcNAc}_{2}$ is no longer normally processed. In plants, flies and mammals, this also means that core fucosylation is heavily reduced in keeping with assays showing that the relevant enzymes are dependent, at least in vitro, on the prior action of GlcNAc-TI (9-11).

Unusually, C. elegans possesses three GlcNAc-TI genes ( $g l y-12$, gly-13 and $g l y-14$ ), all of which have been proven to be enzymatically active and all of which need to be deleted in order to abolish GlcNAc-TI activity in vivo $(12,13)$. The three products of the differentiallyexpressed genes have slightly different substrate specificities in that they can either accept $\mathrm{Man}_{3} \mathrm{GlcNAc}_{2}$ or $\mathrm{Man}_{5} \mathrm{GlcNAc}_{2}$, in contrast to the homologues from most other organisms which can transfer GlcNAc to both. A previous MALDI-TOF MS-based screen of the gly-12; gly-13;gly-14 triple knock-out did indeed indicate fucosylation of glycans with compositions suggestive of oligomannosidic structures (13); however, our recent off-line MALDI-TOF MS data demonstrate that not all hexose residues in $C$. elegans $\mathrm{N}$-glycans are mannose, as bisecting $\beta$-galactose on the core $\beta$-mannose and an $\alpha$-galactose modification of the a 1,3-mannose have been found (14). As part of our continuing studies on the diversity of wild-type and mutant $C$. elegans $\mathrm{N}$-glycomes, we have reappraised that of the gly-12; gly-13;gly-14 triple knock-out and reveal that also this mutant expresses unusual $\mathrm{N}$-glycans containing up to three galactose substitutions of mannose residues.

\section{Methods}

\section{Biological material}

The C. elegans $g l y-12 ; g l y-13 ; g l y-14$ strain ( $g l y-14$ (III);gly-12 gly13(X)) was previously prepared as described by crossing the gly-12(id47), gly-13(ok712) and gly-14(id48) alleles (13) and was maintained under standard conditions; mixed stages were cultivated at $20{ }^{\circ} \mathrm{C}$ (160 rpm; 4-6 days) in liquid culture with $E$. coli OP50 in standard S complete medium prior to harvesting and purification by sucrose density centrifugation (15). Harvested worms were boiled in water for 10 minutes to heat-inactivate proteases prior to homogenisation. The homogenates were transferred in glass flasks and pepsinised overnight at $37^{\circ} \mathrm{C}$. Glycopeptides were purified by cation exchange chromatography (Dowex $50 \mathrm{~W} \times 8$; elution with $0.5 \mathrm{M}$ ammonium acetate, $\mathrm{pH}$ 6) followed by G25 gel filtration.

\section{$\mathrm{N}$-glycan release, purification and labelling}

Enzymatic release of $\mathrm{N}$-glycans from worm peptic glycopeptides was done sequentially using two different peptide:N-glycosidases: first recombinant PNGase F (Roche) was employed under alkaline conditions $(\mathrm{pH} 8.0)$ and the released glycans were separated from the remaining glycopeptides on Dowex $50 \mathrm{~W} \times 8(10 \mathrm{ml}$ resin, with glycans in the $2 \%$ acetic acid 'wash' and glycopeptides in the $0.5 \mathrm{M}$ ammonium acetate eluate). The glycopeptide fraction was desalted, lyophilised and taken up in $\mathrm{pH} 5.0$ buffer prior to treatment with native almond PNGase A (Roche; at $\mathrm{pH} 5.0$ ) and another round of Dowex 50W $\times 8$ 
chromatography. Both $\mathrm{N}$-glycan pools were separately purified by solid-phase extraction using non-porous graphitised carbon (nPGC; elution with $40 \%$ acetonitrile) and LiChroprep ${ }^{\circledR} \mathrm{RP}-18$ (C18; elution with water) prior to pyridylamination as previously described (16-18). For a fuller description, refer to the Supplement.

\section{Mass spectrometric analysis}

The N-glycomes of the different strains were profiled by MALDI-TOF MS (Autoflex Speed, Bruker Daltonics, Germany) in positive ion mode using FlexControl 3.4 software. PAlabelled N-glycans were fractionated by 2D-HPLC as described below and all HPLC peaks were collected and examined by MALDI-TOF MS, using 6-aza-2-thiothymine (ATT) as matrix; MS/MS to confirm the composition of all proposed structures was performed by laser-induced dissociation (the typical precursor ion selector window of $\pm 0.6 \%$ being adjusted as considered appropriate for samples containing multiple glycans). The detector voltage was generally set at $1977 \mathrm{~V}$ for MS and $2133 \mathrm{~V}$ for MS/MS; 1000-3000 shots from different regions of the sample spots were summed. Spectra were processed with the manufacturer's software (Bruker Flexanalysis 3.3.80) using the SNAP algorithm with a signal/noise threshold of 6 for MS (unsmoothed) and 3 for MS/MS (four-times smoothed). In total approximately 3500 MS and MS/MS spectra were manually interpreted on the basis of the mass, fragmentation pattern and results of chemical and enzymatic treatments; isomeric structures present in different 2D-HPLC fractions were defined on the basis of comparisons of the aforementioned parameters. At least five MS/MS fragment ions were used to aid definition of each of the structures. LC-MS ${ }^{\mathrm{n}}$ was performed on a $\mathrm{Gal}_{3} \mathrm{Man}_{4} \mathrm{GlcNAc}_{2}$ structure as well as two $\mathrm{Man}_{7} \mathrm{GlcNAc}_{2}$ isomers as previously described (14).

\section{HPLC purification of $\mathrm{N}$-glycans}

Separation of PA-labelled glycans was carried out on a Shimadzu HPLC system equipped with a fluorescence detector (RF 10 AXL). First the glycans were fractionated by NP-HPLC using a Tosoh Amide- 80 column $(4.6 \times 250 \mathrm{~mm})$; dried samples were taken up in $50 \mu \mathrm{l}$ of a 25:75 mixture of buffer A (10 mM ammonium formate, $\mathrm{pH} 7$ ) and buffer $\mathrm{B}$ (95\% acetonitrile) prior to injection and the following gradient was applied: 0-5 mins, $75 \% \mathrm{~B}$; 5-15 mins, $75-65 \%$ B; $15-40$ mins, $65 \%$ B; 40-55 mins, $65-57 \%$ B; followed by a return to the starting conditions. Selected fractions were then subject to RP-HPLC on a Hypersil ODS column ( $5 \mu \mathrm{m}, 4 \times 250 \mathrm{~mm}$; Agilent), whereby buffer $\mathrm{C}$ was $0.1 \mathrm{M}$ ammonium acetate, $\mathrm{pH}$ 4 , and buffer D was 30\% (v/v) methanol. Gradients of increasing methanol (1\% buffer D per minute) were applied. Fluorescence was recorded at $320 \mathrm{~nm}$ (excitation) and $400 \mathrm{~nm}$ (emission). The columns were calibrated daily in terms of glucose units (g.u.) with a pyridylaminated partial dextran hydrolysate. Various modifications of $\mathrm{N}$-glycans have different effects on retention time as compared to the 'parent' structure: a 1,3-fucose and a 1,6-fucose resulting in either 2 g.u. earlier or 3 g.u. later RP-HPLC elution; bisecting galactose in 3 g.u. earlier elution on RP-HPLC; intersecting galactose in 1 g.u. earlier elution on RP-HPLC; methylation in 0.3 g.u. earlier on NP-HPLC, but later elution on RPHPLC. 


\section{Structural elucidation using exoglycosidases and chemical treatment}

In general, a $1 \mu \mathrm{l}$ aliquot of a previously dried and redissolved HPLC fraction was mixed with $0.2 \mu \mathrm{l}$ exoglycosidase and $0.8 \mu \mathrm{l} 100 \mathrm{mM}$ ammonium acetate solution, $\mathrm{pH}$ 5.0; after an overnight incubation at $37^{\circ} \mathrm{C}, 0.5 \mu \mathrm{l}$ aliquot of the mixture was analysed by MALDI-TOF MS. Exoglycosidases employed were: $a$-galactosidase from green coffee beans (Sigma, 11 $\mathrm{mU}$ ), recombinant $\beta$-galactosidase from Aspergillus niger (produced in-house, $144 \mu \mathrm{U}$ ), Aspergillus a 1,2-specific mannosidase (Prozyme, $4 \mu \mathrm{U}$ ), jack bean a-mannosidase (either from Sigma-Aldrich, $6.25 \mathrm{mU}$, New England Biolabs, $400 \mathrm{mU}$, or Prozyme, $30 \mathrm{mU}$ ), recombinant Xanthomonas manihotis a 1,2/3- or a 1,6-mannosidases (New England Biolabs, 6 - $8 \mathrm{U}$ ), microbial a 1,2-specific fucosidase (E-FUCM from Megazyme, $3 \mathrm{mU}$ ) and a-Lfucosidase from bovine kidney (Sigma-Aldrich, $10 \mathrm{mU}$ ). Specificities of these glycosidases have been previously described by us or others (19-25); as discussed below, release of some $a$-mannose and $\beta$-galactose residues is limited by mutual steric hindrance. For removal of a 1,2/3-linked fucose or methylfucose, glycan samples were dried in a Speed-Vac and then incubated with $3 \mu \mathrm{l}$ of $48 \%$ (w/v) hydrofluoric acid (HF) on ice for 24 hours, before evaporation in a SpeedVac. Chemically or enzymatically treated glycans were generally reanalysed, unless otherwise stated, by MALDI-TOF MS and MS/MS without further purification.

\section{Results}

\section{Overall glycome of a $\mathrm{N}$-acetylglucosaminyltransferase I null mutant}

Previously, the N-glycome of the C. elegans gly-12;gly-13;gly-14 triple GlcNAc-TI knockout strain was profiled by mass spectrometry, but only compositions of the hydrazinereleased structures were described (13); since then, it has become obvious that nematode glycomes are not as simple as was thought. In order to resolve specific structural details, glycans were released serially with PNGase F and PNGase A; such a procedure is necessary as only use of the latter enzyme, and not the former, can yield core a 1,3-fucosylated structures. The pools were separately labelled with 2-aminopyridine as a fluorescent tag, screened by MALDI-TOF-MS and then subject to 2D-HPLC using NP-HPLC followed by RP-HPLC of selected fractions; alternatively, in another experiment, only PNGase A and a single round of RP-HPLC was employed (see Figure 1 as well as Supplementary Figures 1-3). The major N-glycan in the glycome was $\mathrm{Hex}_{5} \mathrm{HexNAc}_{2}$ as defined by its mass $(\mathrm{m} / \mathrm{z}$ 1313 or 1335 as either $[\mathrm{M}+\mathrm{H}]^{+}$or $[\mathrm{M}+\mathrm{Na}]^{+}$) as opposed to $\mathrm{Hex}_{3} \mathrm{HexNAc}_{2} \mathrm{Fuc}_{0-1}$ in the wild-type (26). The expectation that the major glycan would be $\mathrm{Man}_{5} \mathrm{GlcNAc}_{2}$ when GlcNAc-TI activity is lacking was met, as the RP-HPLC retention time (7.4 g.u.) is the same as for the relevant standard; therefore, this structure was not further analysed. However, there were a range of other glycan masses and, in total, our off-line MALDI-TOF MS/MS approach allowed us to detect more glycans than previously found by MALDI-TOF MS profiling alone of the glycome of this mutant (Supplementary Table); differences between the wild-type and mutant strains are reflected in the absence of certain RP-HPLC peaks or of individual 'mutant-specific' MS signals from the former (Supplementary Figure 3). 


\section{Multiple isomers of $\mathrm{Hex}_{4-8} \mathrm{HexNAc}_{2}$}

There were a number of $\mathrm{Hex}_{4-5} \mathrm{HexNAc}_{2}$ glycans detected in individual 2D-HPLC fractions (Figure $1 \mathrm{~A}$ and $\mathrm{B}$ ) of rather early retention time and, considering our recent discovery of bisecting $\beta$-galactose and antennal a-galactose on $C$. elegans glycans (14), we subjected these isomers to galactosidase digestion. Indeed, the $\mathrm{Hex}_{4} \mathrm{HexNAc}_{2}$ glycan eluting at 4.2 g.u. from the RP-HPLC column (as a second dimension; Figure 1A) was respectively amannosidase resistant, but $\beta$-galactosidase sensitive (Figure $2 \mathrm{~A}-\mathrm{C}$ ) and has a different fragmentation pattern as compared to a 'normal' $\mathrm{Man}_{4} \mathrm{GlcNAc}_{2}$ structure (Figure $2 \mathrm{H}$ and I). On the other hand, the $\mathrm{Hex}_{5} \mathrm{HexNAc}_{2}$ glycan also eluting at 4.2 g.u. (Figure 1B) was only $\beta$ galactosidase sensitive once one mannose residue was removed (whereby a-mannosidasedigestion did not result in a detectable shift in RP-HPLC retention time; see Figure 2 D-G, J$\mathrm{M})$. As we previously observed that mannose and bisecting galactose residues can sterically hinder access by glycosidases (24), the properties of these minor $\mathrm{Hex}_{4-5} \mathrm{HexNAc}_{2}$ glycans were compatible with the presence of bisecting $\beta$-galactose. On the other hand, other $\mathrm{Hex}_{3-4} \mathrm{HexNAc}_{2}$ glycans were completely sensitive to jack bean $\alpha$-mannosidase as is expected for $\mathrm{Man}_{3-4} \mathrm{GlcNAc}_{2}$ structures (Supplementary Figure 4 A, B, F-I).

Rather unexpected was the range of $\mathrm{Hex}_{6} \mathrm{HexNAc}_{2}$ isomers; seven structures were detected in different RP-HPLC fractions (Figure 1D). Two of these were standard closely-eluting forms of $\mathrm{Man}_{6} \mathrm{GlcNAc}_{2}$ with different locations for the single a 1,2-mannose residue (Supplementary Figure 5) in keeping with previous studies (27). The other five $\mathrm{Hex}_{6} \mathrm{HexNAc}_{2}$ isomers were, though, found by their $\mathrm{a}$ - or $\beta$-galactosidase sensitivities to contain galactose residues. Indeed, the major $\mathrm{Hex}_{6} \mathrm{HexNAc}_{2}$-containing 2D-HPLC fraction (RP 5.9 g.u.; Figure 1D) was concluded to contain three forms of $\mathrm{Hex}_{6} \mathrm{HexNAc}_{2}$ only resolved by a further round of RP-HPLC following a 1,2-mannosidase treatment which removed one residue each from the two aforementioned oligomannosidic forms; the resistant isomer in this fraction, however, lost two mannose residues upon subsequent incubation with 'unspecific' jack bean a-mannosidase (Figure $3 \mathrm{~A}-\mathrm{C}$ ). The resulting $\mathrm{Hex}_{4} \mathrm{HexNAc}_{2}$ product eluting at 7.9 g.u. (Figure 3C) could be digested down to

Mana 1,6Man $\beta 1,4 \mathrm{GlcNAc} \beta 1,4 \mathrm{GlcNAc}$ by subsequent $\beta$-galactosidase and $\alpha 1,3-$ mannosidase treatment (Figure $3 \mathrm{D}-\mathrm{G}$ ) and it was, therefore, concluded that the original structure contained an intersecting $\beta$-galactose (the term intersecting being originally coined for Dictyostelium glycans containing GlcNAc in the same position (28)). In contrast, the $\mathrm{Gal}_{1} \mathrm{Man}_{5} \mathrm{GlcNAc}_{2}$ variant in the 4.0 g.u. RP-HPLC fraction (fourth isomer; Figure 1D) was digested by jack bean a-mannosidase to a product co-eluting with a previously described bisected form of $\mathrm{Gal}_{1} \mathrm{Man}_{3} \mathrm{GlcNAc}_{2}$ (Figure $3 \mathrm{M}$ and N; see Ref. (14)). A fifth isomer required prolonged $\beta$-galactosidase digestion in order to lose two galactose residues, presumably from both the intersecting and bisecting positions, to yield a structure co-eluting with a form of $\mathrm{Man}_{4} \mathrm{GlcNAc}_{2}$ (Figure $3 \mathrm{H}-\mathrm{L}$ ). A sixth form required a sequential digestion with a-galactosidase and a-mannosidase to result in a $\mathrm{Hex}_{4} \mathrm{HexNAc}_{2}$ structure with the same elution time (4.2 g.u.) as a bisected $\mathrm{Gal}_{1} \mathrm{Man}_{3} \mathrm{GlcNAc}_{2}$ (Figure 4 A-D), whereas the seventh form of $\mathrm{Hex}_{6} \mathrm{HexNAc}_{2}$ was sensitive to both a-mannosidase and a-galactosidase, whereby digestion with the latter enzyme resulted in a glycan co-eluting with a $\mathrm{Man}_{5} \mathrm{GlcNAc}_{2}$ standard (Figure 4 E-H). Thus, the five non-oligomannosidic $\mathrm{Hex}_{6} \mathrm{HexNAc}_{2}$ 
isomers were forms of $\mathrm{Man}_{4-5} \mathrm{GlcNAc}_{2}$ decorated with one or two galactose residues, which were either intersecting $\beta$-galactose, bisecting $\beta$-galactose or terminal $a$-galactose.

This trend to multiple galactosylation positions was continued amongst nonoligomannosidic isomers of $\mathrm{Hex}_{7-8} \mathrm{HexNAc}_{2}$. Two example structures were resistant to jack bean a-mannosidase, while a-galactosidase digestion resulted in small forward shifts to the same elution time as intersected/bisected forms of $\mathrm{Hex}_{6-7} \mathrm{HexNAc}_{2}$ (Figure $4 \mathrm{I}$-Q; see also Supplementary Figure 6). A further proof for the linkages of the galactose residues and an explanation for the a-mannosidase resistance came from LC-ESI-MS ${ }^{2}$ data on one of these structures $\left(\mathrm{Gal}_{3} \mathrm{Man}_{4} \mathrm{GlcNAc}_{2}\right)$, which showed differences in the pattern of cross-ring cleavages as compared to two 'standard' $\mathrm{Man}_{7} \mathrm{GlcNAc}_{2}$ isomers (Figure 5).

\section{Isomers of $\mathrm{Hex}_{3-7} \mathrm{HexNAc}_{2} \mathrm{Fuc}_{1}$}

Fucosylation of $\mathrm{Hex}_{5} \mathrm{HexNAc}_{2}$ has been previously noted in the $C$. elegans triple GlcNAc-TI knock-out as well as in GlcNAc-TI-deficient mammalian cell lines $(13,29)$, which is potentially due to GlcNAc-TI-independent core a 1,6-fucosylation. In the nematode, there were multiple $\mathrm{Hex}_{5} \mathrm{HexNAc}_{2} \mathrm{Fuc}_{1}$ isomers in both the PNGase $\mathrm{F}$ and PNGase A-released glycan pools (Figure $1 \mathrm{C}$ and F). As PNGase F cannot release glycans with proximal core a 1,3-fucose (30), it was assumed that $\mathrm{Hex}_{5} \mathrm{HexNAc}_{2} \mathrm{Fuc}_{1}$ structures in this pool could either be core a 1,6-fucosylated or carry a 1,2-fucose on a bisecting galactose, both known motifs in C. elegans; in contrast, the PNGase A-released pool would be expected to contain core a 1,3-fucosylated structures as the nematode core a 1,3-fucosyltransferase can indeed accept $\mathrm{Man}_{3-5} \mathrm{GlcNAc}_{2}$ as substrates $(31,32)$. All three positions (core a 1,3, core a 1,6 and outer $a 1,2)$ for fucosylation were indeed proven on the basis of glycosidase digests. Both types of core fucosylation could be proposed for a-mannosidase-sensitive forms of $\mathrm{Man}_{5} \mathrm{GlcNAc}_{2} \mathrm{Fuc}_{1}$ (4.7 and 11.0 g.u.), whereby the late-eluting form of which lost a fucose residue upon bovine a-fucosidase treatment (Figure $6 \mathrm{~A}-\mathrm{E}$ ); the difference in RP-HPLC elution (early or late) of such glycans due to either 3- or 6-core fucosylation is a previouslynoted effect (33) and also correlates with the occurrence in either the PNGase A- or Freleased pools. Furthermore, the relative intensity of the $\mathrm{m} / \mathrm{z} 300$ and $446 \mathrm{GlcNAc}_{1} \mathrm{Fuc}_{0-1^{-}}$ PA Y1-fragment ions is somewhat diagnostic (4:6 for the 4.7 g.u. isomer as compared to 2:8 for the one at 11.0 g.u), as the a 1,3-fucose residue is more labile in MS/MS than one in a1,6-linkage.

In contrast, two other $\mathrm{Hex}_{5} \mathrm{HexNAc}_{2} \mathrm{Fuc}_{1}$ isomers displayed unfamiliar fragmentation patterns or limited a-mannosidase sensitivity; one (eluting at 4.1 g.u. in the PNGase Freleased pool; Figure 1C) lacked an $\mathrm{m} / \mathrm{z} 446$ Y-fragment ion and so was concluded not to be core fucosylated (Figure 6F). Indeed it lost a fucose residue after a 1,2-fucosidase treatment and the pattern of galactosidase resistance and mannosidase sensitivity together with the shift in elution upon fucosidase digestion was taken as indicating that this glycan was fucosylated on the bisecting galactose residue (Figure 6 F-J and N). The other isomer ( 2.8 g.u. in the PNGase A-released pool; Figure 1F) showed an approximately 4:6 ratio of $\mathrm{m} / \mathrm{z}$ 300 and 446 Y-fragment ion intensities (Figure 6K) and jack bean a-mannosidase digestion resulted in a product (Figure $6 \mathrm{~L}$ and $\mathrm{M}$ ) co-eluting with a core a 1,3-fucosylated form of $\mathrm{Gal}_{1} \mathrm{Man}_{3} \mathrm{GlcNAc}_{2}$ proven to occur in the fut-6;fut-8 mutant strain (24). 
Other than $\mathrm{Hex}_{5} \mathrm{HexNAc}_{2} \mathrm{Fuc}_{1}$, there were a number of other monofucosylated glycans. For instance, two forms of $\mathrm{HexNAc}_{3-4} \mathrm{HexNAc}_{2} \mathrm{Fuc}_{1}$ were based on paucimannosidic glycans as shown by retention time and/or glycosidase sensitivities (Supplementary Figure 4). Fucosylated forms of $\mathrm{Hex}_{6} \mathrm{HexNAc}_{2}$ were also detected (Figure 1H) in 2D-separated glycans from the PNGase A-released pool. The MS/MS fragmentation pattern and glycosidase sensitivity of one major form ( 3.8 g.u.) led us to conclude that it was an core a 1,3-fucosylated form of an intersected structure (Figure 7 A-C). Another core a 1,3fucosylated a-mannosidase-resistant version of $\mathrm{Hex}_{6} \mathrm{HexNAc}_{2}$, found in the PNGase Areleased pool (2.7 g.u.), co-eluted with a $\mathrm{Gal}_{2} \mathrm{Man}_{4} \mathrm{GlcNAc}_{2}$ structure (found in the PNGase F pool at 4.2 g.u.) when treated with hydrofluoric acid (Figure 7 D-F), while a slightly-later eluting version ( 2.9 g.u.) was judged by loss of only one residue upon a-mannosidase treatment and MS/MS spectrum to probably contain a bisected $\beta$ - and an antennal $\alpha$ galactose (Figure $7 \mathrm{~N}$ and $\mathrm{O}$ ). Co-eluting with the latter structure in a 1D-HPLC fraction was a $\mathrm{Hex}_{7} \mathrm{HexNAc}_{2} \mathrm{Fuc}_{1}$ glycan, whose pattern of $\mathrm{a}$-mannosidase and $\mathrm{a}$ - or $\beta$ galactosidase digestion was compatible with the presence of a bisecting, an antennal and an intersecting galactose (Figure $7 \mathrm{P}-\mathrm{T}$ ).

Fucosylation of galactose was also observed, as in the case of a third $\mathrm{Hex}_{6} \mathrm{HexNAc}_{2} \mathrm{Fuc}_{1}$ isomer eluting at 6.8 g.u.. While jack bean a-mannosidase could remove one mannose residue from the intact glycan $(\mathrm{m} / \mathrm{z} 1621)$, the fucose residue was sensitive to a 1,2fucosidase (Figure 7 G-I). This fucosidase product co-eluted (5.8 g.u.) with the hydrofluoric acid treated form of the first described $\mathrm{Hex}_{6} \mathrm{HexNAc}_{2} \mathrm{Fuc}_{1}$ suggesting that both shared the same $\mathrm{Hex}_{6} \mathrm{HexNAc}_{2}$ backbone (Figure 7J), which could be serially treated with jack bean amannosidase and $\beta 1$,4-galactosidase to yield a 'linear' $\mathrm{Man}_{3} \mathrm{GlcNAc}_{2}$ isomer (Figure $7 \mathrm{~K}$ M). Thus, the 6.8 g.u. isomer is concluded to be a $\mathrm{Man}_{5} \mathrm{GlcNAc}_{2}$ carrying an intersecting Fuca 1,2Gal modification absent from the wild-type (Supplementary Figure 3).

\section{Methylation of fucose and mannose residues}

In addition to the various $\mathrm{Hex}_{3-8} \mathrm{HexNAc}_{2} \mathrm{Fuc}_{0-1}$ glycans, we detected structures with either a second fucose and/or methylated residues in a number of fractions. Methylation results in earlier elution on the NP-HPLC column, but generally later elution in the RP-HPLC second dimension, as compared to the parent non-methylated structure, while the position of fucose attachment also affects RP-HPLC retention time. Unfortunately, methylation generally prevents the action of glycosidases; only methylated fucose can be partially released by hydrofluoric acid treatment. Thus, for these structures we rely primarily on MS/MS data for the structural annotation, whereby loss of $160 \mathrm{Da}$ is indicative of a methylated fucose, loss of $176 \mathrm{Da}$ is due to a terminal methylated mannose and, e.g., an $\mathrm{m} / \mathrm{z} 841 \mathrm{Y}$-fragment is compatible with methylation of the a1,3-mannose (Figure 8).

Based on the fragmentation pattern and by analogy to characterised glycans with a lower degree of modification from this mutant, we conclude that (i) $\mathrm{Man}_{4} \mathrm{GlcNAc}_{2}$ can be present in mono- and dimethylated as well as a difucosylated forms (Figure 8 A-C); (ii) there are fucose or methylfucose residues on either the intersecting and bisecting galactose of isomers of $\mathrm{Hex}_{5-7} \mathrm{HexNAc}_{2} \mathrm{Fuc}_{1-2}$ as judged also by enzymatic treatment data (Figure 8 D-F and R$\mathrm{T})$; there are a further five isomers of $\mathrm{Hex}_{6} \mathrm{HexNAc}_{2} \mathrm{Fuc}_{1} \mathrm{Me}_{1}$ with varying patterns of $\mathrm{Y} 3$ 
ions indicative of core or antennal fucosylation or methylation of either hexose or fucose residues (Figure $8 \mathrm{G}-\mathrm{K}$ ) and $\mathrm{Hex}_{6} \mathrm{HexNAc}_{2} \mathrm{Fuc}_{0-2}$ structures can carry between one and four methyl groups either on fucose or mannose residues (Figure $8 \mathrm{~L}-\mathrm{Q}$ ). A fraction containing one isomer of $\mathrm{Hex}_{6} \mathrm{HexNAc}_{2} \mathrm{Fuc}_{1} \mathrm{Me}_{1}(\mathrm{~m} / \mathrm{z}$ 1657) was incubated with either jack bean $\mathrm{a}$ mannosidase or Aspergillus $\beta$-galactosidase; the pattern of sensitivity to the former and resistance to the latter (Supplementary Figure 7) was compatible with the methylfucose residue substituting the intersecting galactose rather than a mannose.

\section{Discussion}

Overall it appears that not only does ablation of a key enzymatic step in the processing of $\mathrm{N}$ glycans in a multicellular organism result in appearance of unexpected modifications (in this case intersecting galactose analogous to the intersecting GlcNAc in Dictyostelium (28)), but also shows that there is conservation of 'wobble' in the specificity of core a1,6fucosyltransferase. The resulting structures are, in part, rather resistant to glycosidase digestion: we sought to explain the inability to remove certain theoretically 'free' residues by modelling of selected predicted glycan structures (Supplementary Figure 8). Certainly, the presence of bisecting and intersecting residues often leads to a-mannosidase resistance, as also observed for Penicillium, Dictyostelium or mammalian glycans when a bisecting $\mathrm{Gal}_{\mathrm{f}}$ or GlcNAc is present (34-36); conversely, sometimes spatially-close mannose residues must be removed before bisecting/intersecting $\beta 1,4$-galactose can be cleaved. Generally, direct galactosylation of mannose residues is, based on our current knowledge, rather rare in eukaryotic N-glycans; other than $C$. elegans, exceptions include galactofuranosylation in Penicillium and Aspergillus $(34,37)$ and $\beta 1,6$-galactosylation on keyhole limpet haemocyanin (38).

It is also obvious from the proposed structures that there is a tendency for $\mathrm{Man}_{4} \mathrm{GlcNAc}_{2}$ based glycans to lack the outer a 1,6-mannose (M6) rather than the outer a 1,3-mannose (M7) substituting the core a1,6-mannose, which would suggest a preference during biosynthesis. Interestingly, Golgi mannosidase II (designated AMAN-2 in C. elegans) is proposed to remove outer a 1,6-mannose first $(39,40)$; however, this is widely considered to be a GlcNAc-transferase I dependent enzyme $(41,42)$, just as is the case for FUT- 8 core a 1,6-fucosyltransferase $(10,11)$, as determined by in vitro assays of the two nematode and mammalian enzymes. However, the current study, as well as others on mammalian cells $(29,43)$, suggest that core a 1,6-fucosylated glycans can be detected even when GlcNActransferase I is absent. The most recent data indicate that mammalian FUT- 8 can indeed fucosylate specific Man ${ }_{5} \mathrm{GlcNAc}_{2}$-containing peptides or proteins, but confirm that the 'free' glycan, as well as some glycoproteins, lacking the non-reducing GlcNAc are not substrates (44); on the other hand, the action of the nematode core a 1,3-fucosyltransferase FUT-1 is, unlike plant and insect forms, already known to be actually inhibited by the presence of the GlcNAc on the a 1,3-mannose (31,32); the continued presence of proximal core a 1,3-fucose in the triple GlcNAc-TI mutant is in accordance with the results of Western blotting with anti-horseradish peroxidase (Supplementary Figure 1). Our data here would also be compatible with a partial degree of independence in vivo of Golgi mannosidase II from the prior action of GlcNAc-transferase I. 
We have detected fucose on four positions (core and antennal) of $\mathrm{N}$-glycans from this triple mutant with maximally three fucose residues per glycan (e.g., in $\mathrm{Hex}_{6} \mathrm{HexNAc}_{2} \mathrm{Fuc}_{3} \mathrm{Me}_{2}$; $\mathrm{m} / \mathrm{z}$ 1941) rather than five positions in the wild-type (26), while methylation still occurs at a detectable level. Thereby, many nematode-specific features, found in the related parasitic worms Haemonchus contortus (45) and Oesophagostomum dentatum (46), are more-or-less absent such as phosphorylcholine on antennal GlcNAc (in accordance with blotting experiments, see Supplementary Figure 1 and (47)), distal core a 1,3-fucose (as the core a 1,6-mannose, which blocks the action of the relevant FUT-6 (48), tends to be still present on the glycans in triple GlcNAc-TI knockout) and galactosylation of core a1,6-fucose (49). The latter motif is recognised by CGL2 which can arrest larval development of $H$. contortus and $C$. elegans, whereas the single $g l y-13$ knock-out is resistant to this lectin, probably due to a lack of this epitope $(49,50)$. On the other hand, the continued presence of core a 1,3fucose and of methylation in the triple mutant explains the wild-type-like sensitivity of this strain to another nematoxic lectin, CCL2 (51), and the partial sensitivity to tectonin, a protein which probably binds methylated $\mathrm{N}$-glycans (52).

However, many of the $\mathrm{N}$-glycans of the triple knockout still carry multiple fucose and galactose residues - thereby, we observe a switch to the previously undescribed modification at the intersecting position. Thus, there seems to be a need to make up for 'missing' residues by making use of otherwise unseen glycosylation events. It can be that the Golgi of a knockout worm is seeking to 'self-correct' similarly to the case in glycosylation-defective mammalian cells, where loss of GlcNAc transferase II results in a shift from multiple single LacNAc caps to the expression of longer linear polyLacNAc (53). Also, it can be that lack of a major Golgi enzyme may result in alterations in Golgi morphology as has been reported for the case when GlcNAc transferase V, but not GlcNAc transferase I, is absent from mutant Chinese hamster ovary cells (54). Some of the shifts in the glycome are reflected in the biosynthetic scheme shown in Supplementary Figure 2, whereby the usual core fucosylation events as well as the ability to generate antennae are affected. Speculatively, there are various explanations for the unusual glycan modifications in the triple knockout: either (i) $\beta 1,4$-galactosyl- and a 1,2-fucosyltransferases normally acting on the core $\beta$-linked mannose are modifying the a 1,6-mannose due to the 'traffic jam' of $\mathrm{Man}_{5} \mathrm{GlcNAc}_{2}$ in the Golgi, (ii) these or other enzymes are mis-localised within the Golgi or (ii) novel low-abundance glycosyltransferases now have the access to sufficient amounts of substrate in order that the novel structures can be observed. Certainly, our off-line 2D-LC-MS/MS-based study is not just another demonstration of the infinite variety of glycosylation events in this apparently 'simple' model organism or an explanation for sensitivities to selected nematoxic agents, but is another indication that glycosyltransferases can be more promiscuous in terms of substrate specificity than suggest by the results of in vitro assays.

\section{Supplementary Material}

Refer to Web version on PubMed Central for supplementary material.

\section{Acknowledgements}

This work was funded in part by the Austrian Fonds zur Förderung der wissenschaftlichen Forschung (FWF; grants P 30021 to S.Y., P23922 and P29466 to I.B.H.W. and P21946 and P25058 to K.P.). S.Y. and K.P. are FWF Fellows. 
We also thank Dr. Martin Dragosits for the recombinant $\beta$-galactosidase, Daniel Malzl for help with figure preparation and Dr. Niclas Karlsson for access to the LTQ mass spectrometer.

\section{References}

1. Larkin A, Imperiali B. The expanding horizons of asparagine-linked glycosylation. Biochemistry. 2011; 50:4411-4426. [PubMed: 21506607]

2. Schachter H. Mgat1-dependent N-glycans are essential for the normal development of both vertebrate and invertebrate metazoans. Semin Cell Dev Biol. 2010; 21:609-615. [PubMed: 20206280]

3. Kang JS, Frank J, Kang CH, Kajiura H, Vikram M, Ueda A, Kim S, Bahk JD, Triplett B, Fujiyama K, Lee SY, et al. Salt tolerance of Arabidopsis thaliana requires maturation of N-glycosylated proteins in the Golgi apparatus. Proc Natl Acad Sci U S A. 2008; 105:5933-5938. [PubMed: 18408158]

4. Shi H, Tan J, Schachter H. N-glycans are involved in the response of Caenorhabditis elegans to bacterial pathogens. Methods Enzymol. 2006; 417:359-389. [PubMed: 17132514]

5. Veyhl J, Dunn RJ, Johnston WL, Bennett A, Zhang LW, Dennis JW, Schachter H, Culotti JG. The directed migration of gonadal distal tip cells in Caenorhabditis elegans requires NGAT-1, a $\beta 1,4-\mathrm{N}-$ acetylgalactosaminyltransferase enzyme. PLoS One. 2017; 12:e0183049. [PubMed: 28817611]

6. Sarkar M, Iliadi KG, Leventis PA, Schachter H, Boulianne GL. Neuronal expression of Mgat1 rescues the shortened life span of Drosophila Mgat ${ }^{1}$ null mutants and increases life span. Proc Natl Acad Sci U S A. 2010; 107:9677-9682. [PubMed: 20457894]

7. Metzler M, Gertz A, Sarkar M, Schachter H, Schrader JW, Marth JD. Complex asparagine-linked oligosaccharides are required for morphogenic events during post-implantation development. EMBO J. 1994; 13:2056-2065. [PubMed: 8187759]

8. Ioffe E, Liu Y, Stanley P. Essential role for complex N-glycans in forming an organized layer of bronchial epithelium. Proc Natl Acad Sci USA. 1996; 93:11041-11046. [PubMed: 8855305]

9. Wilson IBH, Rendic D, Dumic J, Freilinger A, Altmann F, Mucha J, Müller S, Hauser M-T. Cloning and expression of a 1,3-fucosyltransferase homologues from Arabidopsis thaliana. Biochim Biophys Acta. 2001; 1527:88-96. [PubMed: 11420147]

10. Paschinger K, Staudacher E, Stemmer U, Fabini G, Wilson IBH. Fucosyltransferase substrate specificity and the order of fucosylation in invertebrates. Glycobiology. 2005; 15:463-474. [PubMed: 15604090]

11. Wilson JR, Williams D, Schachter $H$. The control of glycoprotein synthesis. $N$-acetylglucosamine linkage to a mannose residue as a signal for the attachment of L-fucose to the asparagine-linked $N$ acetylglucosamine of glycopeptide from $a_{1}$-acid glycoprotein. Biochem Biophys Res Commun. 1976; 72:909-916. [PubMed: 985526]

12. Chen SH, Zhou SH, Sarkar M, Spence AM, Schachter H. Expression of three Caenorhabditis elegans $\mathrm{N}$-acetylglucosaminyltransferase I genes during development. J Biol Chem. 1999; 274:288-297. [PubMed: 9867843]

13. Zhu S, Hanneman A, Reinhold V, Spence A, Schachter H. Caenorhabditis elegans triple null mutant lacking UDP- $N$-acetyl-D-glucosamine: $a-3$-D-mannoside $\beta 1,2 \mathrm{~N}$ acetylglucosaminyltransferase I. Biochem J. 2004; 382:995-1001. [PubMed: 15228383]

14. Yan S, Brecker L, Jin C, Titz A, Dragosits M, Karlsson N, Jantsch V, Wilson IBH, Paschinger K. Bisecting galactose as a feature of N-glycans of wild-type and mutant Caenorhabditis elegans. Mol Cell Proteomics. 2015; 14:2111-2125. [PubMed: 26002521]

15. Brenner S. The genetics of Caenorhabditis elegans. Genetics. 1974; 77:71-94. [PubMed: 4366476]

16. Paschinger K, Hykollari A, Razzazi-Fazeli E, Greenwell P, Leitsch D, Walochnik J, Wilson IBH. The N-glycans of Trichomonas vaginalis contain variable core and antennal modifications. Glycobiology. 2012; 22:300-313. [PubMed: 21983210]

17. Hykollari A, Paschinger K, Eckmair B, Wilson IBH. Analysis of Invertebrate and Protist NGlycans. Methods Mol Biol. 2017; 1503:167-184. [PubMed: 27743366] 
18. Hase S, Ibuki T, Ikenaka T. Reexamination of the pyridylamination used for fluorescence labelling of oligosaccharides and its application to glycoproteins. J Biochem (Tokyo). 1984; 95:197-203. [PubMed: 6706908]

19. Haibach F, Hata J, Mitra M, Dhar M, Harmata M, Sun P, Smith D. Purification and characterization of a Coffea canephora a-D-galactosidase isozyme. Biochem Biophys Res Commun. 1991; 181:1564-1571. [PubMed: 1662502]

20. Dragosits M, Pflugl S, Kurz S, Razzazi-Fazeli E, Wilson IBH, Rendić D. Recombinant Aspergillus $\beta$-galactosidases as a robust glycomic and biotechnological tool. Appl Microbiol Biotechnol. 2014; 98:3553-3567. [PubMed: 24037406]

21. Yamashita K, Ichishima E, Arai M, Kobata A. An a-mannosidase purified from Aspergillus saitoi is specific for a 1,2 linkages. Biochem Biophys Res Commun. 1980; 96:1335-1342. [PubMed: 7437073]

22. Wong-Madden ST, Landry D. Purification and characterization of novel glycosidases from the bacterial genus Xanthomonas. Glycobiology. 1995; 5:19-28. [PubMed: 7772864]

23. Li YT. Studies on the glycosidases in jack bean meal. I. Isolation and properties of a-mannosidase. J Biol Chem. 1967; 242:5474-5480. [PubMed: 12325362]

24. Yan S, Jin C, Wilson IBH, Paschinger K. Comparisons of Caenorhabditis fucosyltransferase mutants reveal a multiplicity of isomeric N-glycan structures. J Proteome Res. 2015; 14:52915305. [PubMed: 26538210]

25. Kubelka V, Altmann F, Staudacher E, Tretter V, März L, Hård K, Kamerling JP, Vliegenthart JFG. Primary structures of the N-linked carbohydrate chains from honeybee venom phospholipase $\mathrm{A}_{2}$. Eur J Biochem. 1993; 213:1193-1204. [PubMed: 8504812]

26. Yan S, Vanbeselaere J, Jin C, Blaukopf M, Wols F, Wilson IBH, Paschinger K. Core Richness of N-Glycans of Caenorhabditis elegans: A Case Study on Chemical and Enzymatic Release. Anal Chem. 2018; 90:928-935. [PubMed: 29182268]

27. Tomiya N, Lee YC, Yoshida T, Wada Y, Awaya J, Kurono M, Takahashi N. Calculated twodimensional sugar map of pyridylaminated oligosaccharides: Elucidation of the jack bean amannosidase digestion pathway of Man9G GlcNAc$_{2}$. Analytical Biochemistry. 1991; 193:90-100. [PubMed: 2042746]

28. Couso R, van Halbeek H, Reinhold V, Kornfeld S. The high mannose oligosaccharides of Dictyostelium discoideum glycoproteins contain a novel intersecting $\mathrm{N}$-acetylglucosamine residue. J Biol Chem. 1987; 262:4521-4527. [PubMed: 3558352]

29. Crispin M, Harvey DJ, Chang VT, Yu C, Aricescu AR, Jones EY, Davis SJ, Dwek RA, Rudd PM. Inhibition of hybrid- and complex-type glycosylation reveals the presence of the GlcNAc transferase I-independent fucosylation pathway. Glycobiology. 2006; 16:748-756. [PubMed: 16672288]

30. Tretter V, Altmann F, März L. Peptide- $N^{4}-(N$-acetyl- $\beta$-glucosaminyl)asparagine amidase F cannot release glycans with fucose attached $\mathrm{a} 1 \rightarrow 3$ to the asparagine-linked $N$-acetylglucosamine residue. Eur J Biochem. 1991; 199:647-652. [PubMed: 1868849]

31. Paschinger K, Rendić D, Lochnit G, Jantsch V, Wilson IBH. Molecular basis of anti-horseradish peroxidase staining in Caenorhabditis elegans. J Biol Chem. 2004; 279:49588-49598. [PubMed: 15364955]

32. Both P, Sobczak L, Breton C, Hann S, Nobauer K, Paschinger K, Kozmon S, Mucha J, Wilson IBH. Distantly-related plant and nematode core a 1,3-fucosyltransferases display similar trends in structure-function relationships. Glycobiology. 2011; 21:1401-1415. [PubMed: 21515584]

33. Yan S, Wilson IBH, Paschinger K. Comparison of RP-HPLC modes to analyse the N-glycome of the free-living nematode Pristionchus pacificus. Electrophoresis. 2015; 36:1314-1329. [PubMed: 25639343]

34. Hykollari A, Eckmair B, Voglmeir J, Jin C, Yan S, Vanbeselaere J, Razzazi-Fazeli E, Wilson IBH, Paschinger K. More than just oligomannose: An N-glycomic comparison of Penicillium species. Mol Cell Proteomics. 2016; 15:73-92. [PubMed: 26515459]

35. Hykollari A, Dragosits M, Rendić D, Wilson IBH, Paschinger K. N-glycomic profiling of a glucosidase II mutant of Dictyostelium discoideum by "off-line" liquid chromatography and mass spectrometry. Electrophoresis. 2014; 35:2116-2129. [PubMed: 24574058] 
36. Allen SD, Tsai D, Schachter H. Control of glycoprotein synthesis. The in vitro synthesis by hen oviduct membrane preparations of hybrid asparagine-linked oligosaccharides containing five mannose residues. J Biol Chem. 1984; 259:6984-6990. [PubMed: 6725278]

37. Wallis GL, Easton RL, Jolly K, Hemming FW, Peberdy JF. Galactofuranoic-oligomannose Nlinked glycans of a-galactosidase A from Aspergillus niger. Eur J Biochem. 2001; 268:41344143. [PubMed: 11488905]

38. Wuhrer M, Robijn ML, Koeleman CA, Balog CI, Geyer R, Deelder AM, Hokke CH. A novel $\operatorname{Gal}(\beta 1-4) \mathrm{Gal}(\beta 1-4) \mathrm{Fuc}(\mathrm{a} 1-6)$-core modification attached to the proximal $N$-acetylglucosamine of keyhole limpet haemocyanin (KLH) N-glycans. Biochem J. 2004; 378:625-632. [PubMed: 14613482]

39. Harpaz N, Schachter H. Control of glycoprotein synthesis. V. Processing of asparagine-linked oligosaccharides by one or more rat liver Golgi $a-D$-mannosidases dependent on the prior action of UDP- $N$-acetylglucosamine: $a-D$-mannoside $\beta$-2- $N$-acetylglucosaminyltransferase I. J Biol Chem. 1980; 255:4894-4902. [PubMed: 6445359]

40. Shah N, Kuntz DA, Rose DR. Golgi a-mannosidase II cleaves two sugars sequentially in the same catalytic site. Proc Natl Acad Sci U S A. 2008; 105:9570-9575. [PubMed: 18599462]

41. Paschinger K, Hackl M, Gutternigg M, Kretschmer-Lubich D, Stemmer U, Jantsch V, Lochnit G, Wilson IBH. A deletion in the Golgi a-mannosidase II gene of Caenorhabditis elegans results in unexpected non-wild type N-glycan structures. J Biol Chem. 2006; 281:28265-28277. [PubMed: 16864579]

42. Moremen KW, Touster O, Robbins PW. Novel purification of the catalytic domain of Golgi amannosidase II. Characterization and comparison with the intact enzyme. J Biol Chem. 1991; 266:16876-16885. [PubMed: 1885615]

43. Yang Q, Wang LX. Mammalian a 1,6-fucosyltransferase (FUT8) is the sole enzyme responsible for the $\mathrm{N}$-acetylglucosaminyltransferase I-independent core fucosylation of high-mannose N-glycans. J Biol Chem. 2016; 291:11064-11071. [PubMed: 27008861]

44. Yang Q, Zhang R, Cai H, Wang LX. Revisiting the substrate specificity of mammalian a 1,6fucosyltransferase (FUT8) reveals that it catalyzes core fucosylation of N-glycans lacking a 1,3arm GlcNAc. J Biol Chem. 2017

45. Paschinger K, Wilson IBH. Two types of galactosylated fucose motifs are present on N-glycans of Haemonchus contortus. Glycobiology. 2015; 25:585-590. [PubMed: 25740940]

46. Jiménez-Castells C, Vanbeselaere J, Kohlhuber S, Ruttkowski B, Joachim A, Paschinger K. Gender and developmental specific N-glycomes of the porcine parasite Oesophagostomum dentatum. Biochim Biophys Acta. 2017; 1861:418-430.

47. Houston KM, Sutharsan R, Steiger CN, Schachter H, Harnett W. Gene inactivation confirms the identity of enzymes involved in nematode phosphorylcholine-N-glycan synthesis. Mol Biochem Parasitol. 2008; 157:88-91. [PubMed: 17920136]

48. Yan S, Serna S, Reichardt NC, Paschinger K, Wilson IBH. Array-assisted Characterization of a Fucosyltransferase Required for the Biosynthesis of Complex Core Modifications of Nematode NGlycans. J Biol Chem. 2013; 288:21015-21028. [PubMed: 23754284]

49. Butschi A, Titz A, Wälti M, Olieric V, Paschinger K, Nöbauer K, Guo X, Seeberger PH, Wilson IBH, Aebi M, Hengartner M, et al. Caenorhabditis elegans $\mathrm{N}$-glycan core $\beta$-galactoside confers sensitivity towards nematotoxic fungal galectin CGL2. PLOS Pathogens. 2010; 6:e1000717. [PubMed: 20062796]

50. Heim C, Hertzberg H, Butschi A, Bleuler-Martinez S, Aebi M, Deplazes P, Künzler M, Stefanic S. Inhibition of Haemonchus contortus larval development by fungal lectins. Parasit Vectors. 2015; 8:425. [PubMed: 26283415]

51. Schubert M, Bleuler-Martinez S, Butschi A, Walti MA, Egloff P, Stutz K, Yan S, Wilson IBH, Hengartner MO, Aebi M, Allain FH, et al. Plasticity of the beta-Trefoil Protein Fold in the Recognition and Control of Invertebrate Predators and Parasites by a Fungal Defence System. PLoS Pathog. 2012; 8:e1002706. [PubMed: 22615566]

52. Wohlschlager T, Butschi A, Grassi P, Sutov G, Gauss R, Hauck D, Schmieder SS, Knobel M, Titz A, Dell A, Haslam SM, et al. Methylated glycans as conserved targets of animal and fungal innate defense. Proc Natl Acad Sci U S A. 2014; 111:E2787-2796. [PubMed: 24879441] 
53. Mkhikian H, Mortales CL, Zhou RW, Khachikyan K, Wu G, Haslam SM, Kavarian P, Dell A, Demetriou M. Golgi self-correction generates bioequivalent glycans to preserve cellular homeostasis. Elife. 2016; 5:e14814. [PubMed: 27269286]

54. Dong Z, Zuber C, Pierce M, Stanley P, Roth J. Reduction in Golgi apparatus dimension in the absence of a residential protein, $\mathrm{N}$-acetylglucosaminyltransferase V. Histochem Cell Biol. 2014; 141:153-164. [PubMed: 24078077] 


\section{Highlights}

Deletion of GlcNAc-TI genes in Caenorhabditis leads to a major glycomic shift Off-line HPLC-MALDI-TOF MS reveals new N-glycan structures

Intersecting galactose with or without a fucose substitution is a new glycan motif 


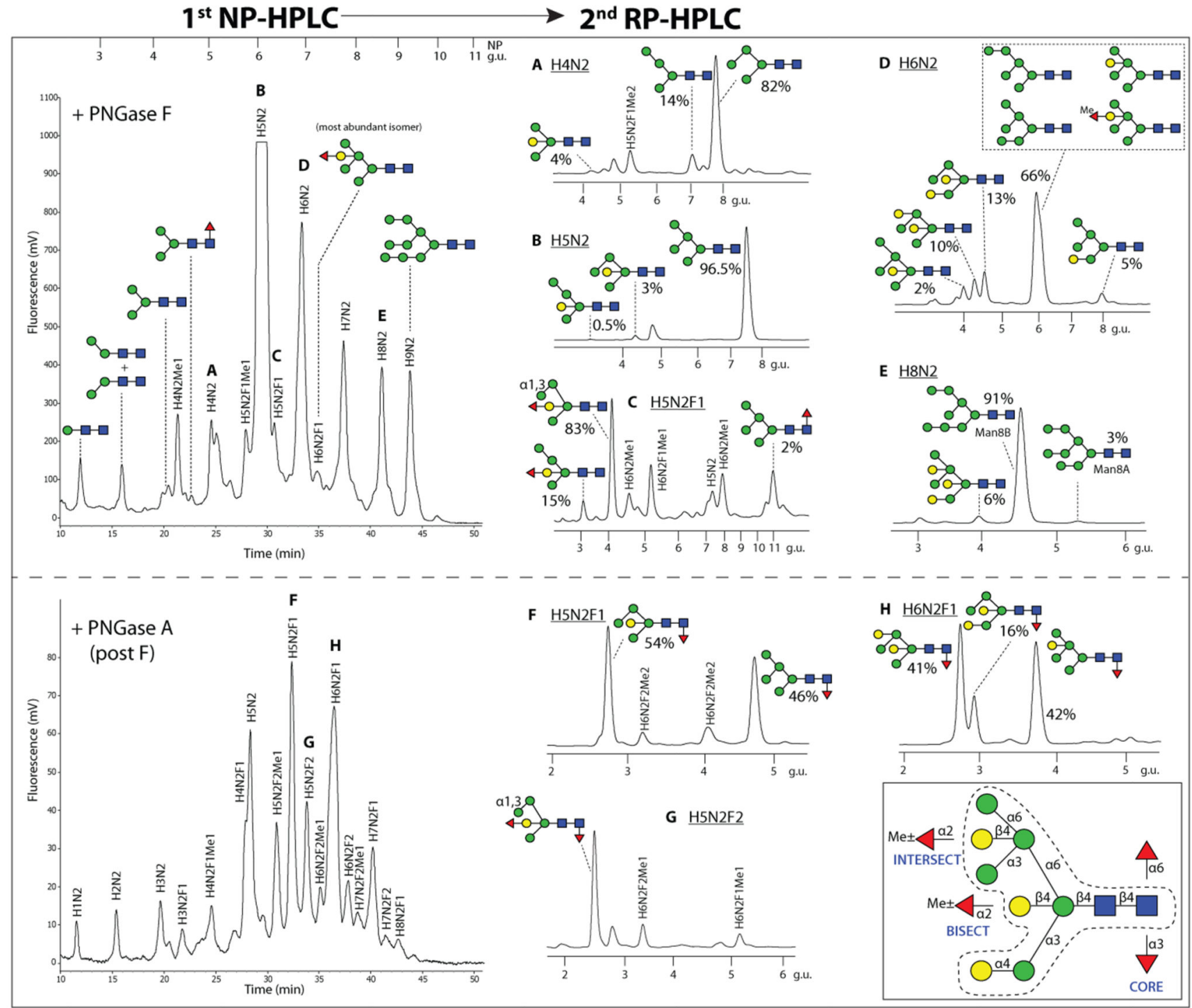

Figure 1. Two-dimensional HPLC of N-glycans released by PNGase F and PNGase A from the $C$. elegans gly-12;gly-13;gly-14 triple mutant.

Glycopeptides were treated serially with PNGase F and A to yield two separate pools of Nglycans which were subject to NP-HPLC; selected fractions (A-H) were further subject to RP-HPLC. The PNGase F profile is dominated by $\mathrm{Man}_{5} \mathrm{GlcNAc}_{2}$ as expected for a mutant lacking GlcNAc-TI, but only due to 2D-HPLC separation could low abundance structural isomers by resolved; for most 'second dimension' RP-HPLC traces, percentages are shown based on integration of fluorescent intensity areas. A schematic structure is given at the bottom-right corner to indicate the proposed linkages of structures which are annotated on the HPLC chromatograms according to the Symbolic Nomenclature for Glycans (circles, mannose or galactose; squares, $N$-acetylglucosamine; triangles, fucose). For the overall $\mathrm{N}$ glycan profile (MS and RP-HPLC) after solely PNGase A digestion as well as the individual 'second dimension' RP-HPLC chromatograms with comparable time windows, refer to Supplementary Figures 1-3. 
MALDI-TOF MS
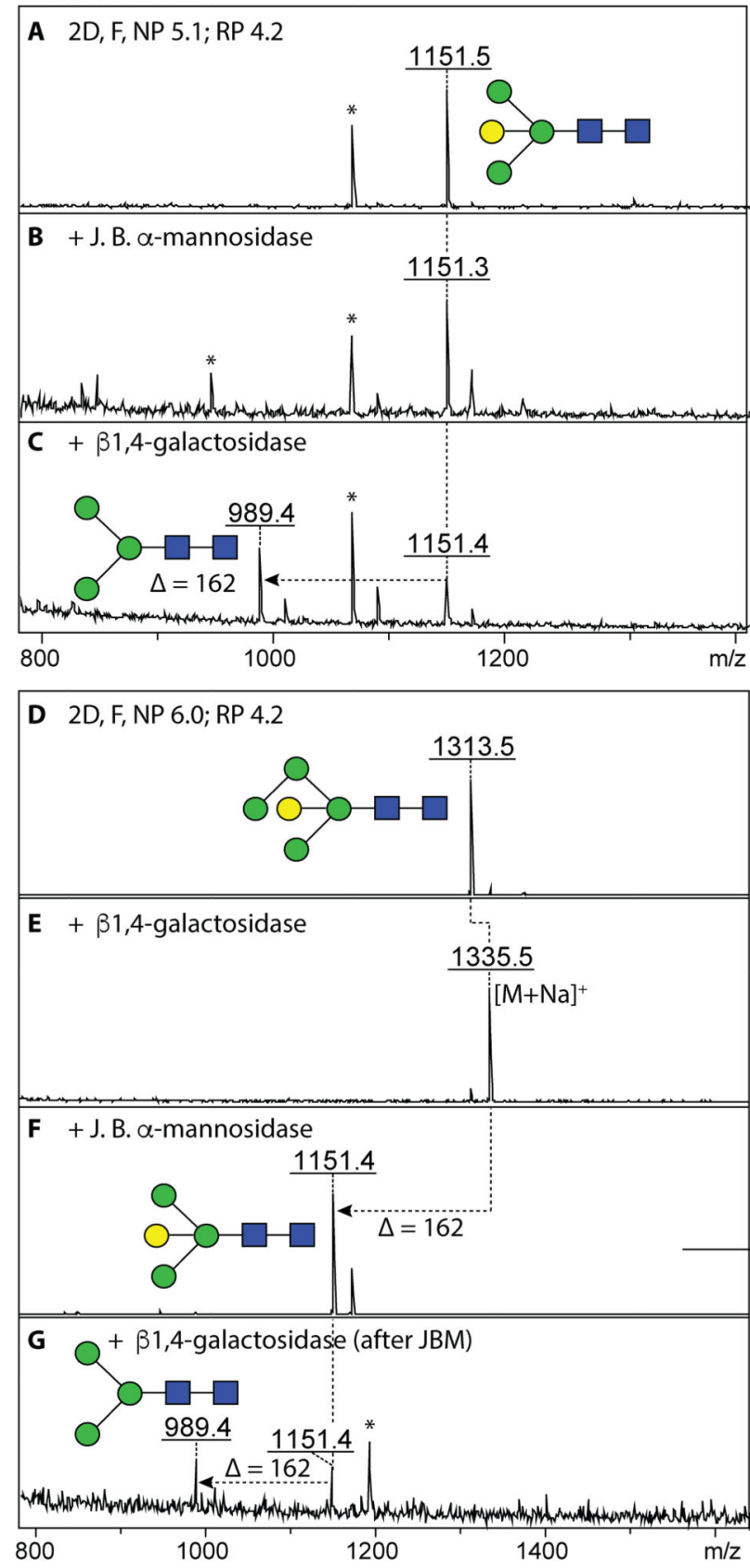

MALDI-TOF MS/MS
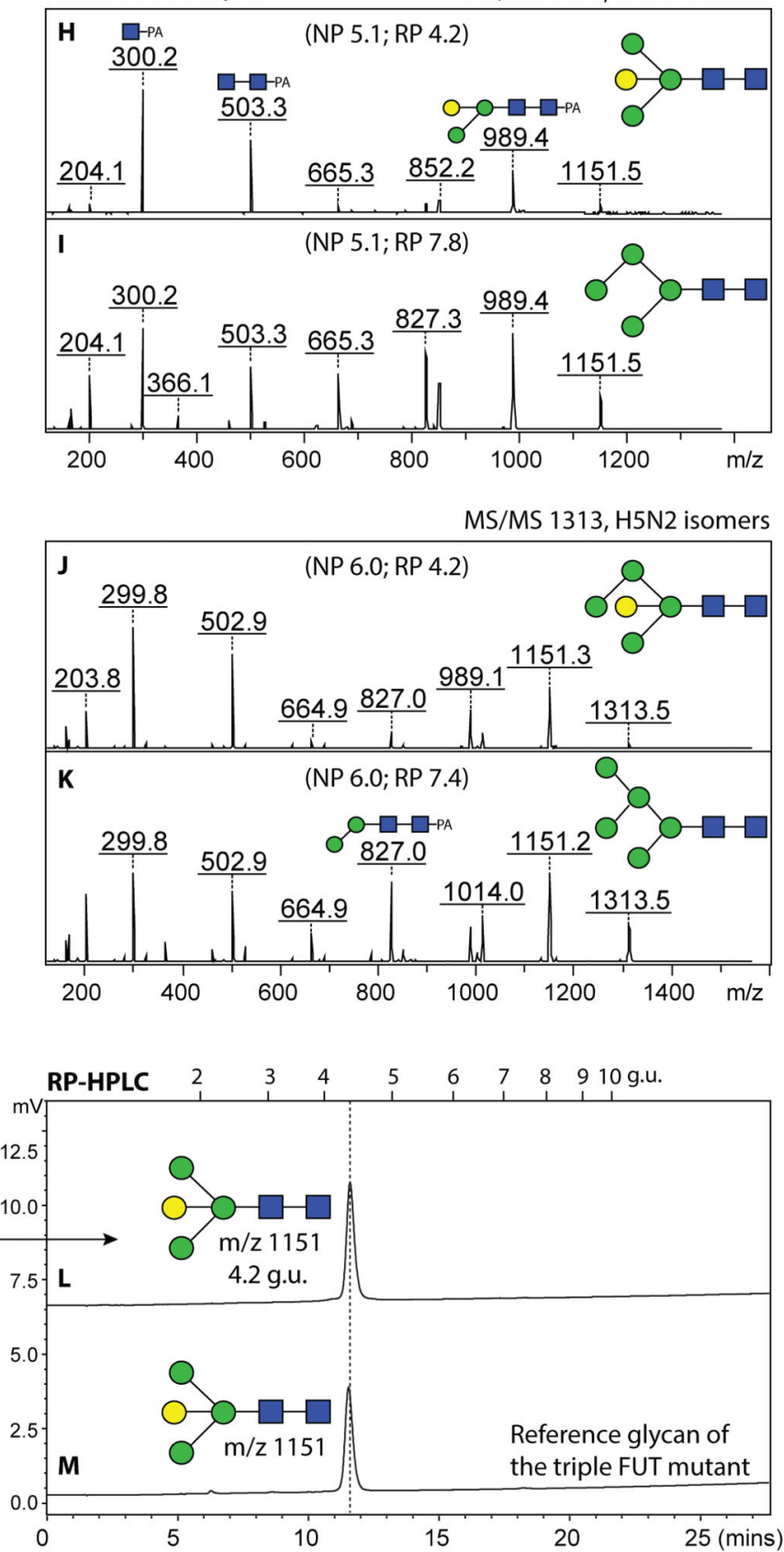

Figure 2. Identification of two paucimannosidic N-glycans carrying bisecting galactose residues. A 2D-HPLC purified glycan $\mathrm{Hex}_{4} \mathrm{HexNAc}_{2}(\mathrm{~m} / \mathrm{z}$ 1151, NP 5.1 g.u.; RP 4.2 g.u) was initially resistant to jack bean a-mannosidase (JBM) but sensitive to $\beta 1$,4-galactosidase (loss of 162) (JBM, A-C); the RP-HPLC elution (4.2 g.u.) of this glycan as well as its MS/MS fragmentation pattern in comparison to a 2D-HPLC isolated $\mathrm{Man}_{4} \mathrm{GlcNAc}_{2}$ structure (H and I) was indicative of the presence of a bisecting galactose on the core pentasaccharide as previously described (14). A Hex ${ }_{5} \mathrm{HexNAc}_{2}$ glycan (m/z 1313, NP 6.0 g.u.; RP 4.2 g.u.) displayed a different fragmentation pattern in terms of relative $\mathrm{Y}$ ion intensities as compared 
to the $\mathrm{Man}_{5} \mathrm{GlcNAc}_{2}$ structure ( $\mathbf{J}$ and $\mathbf{K}$ ) and was resistant to overnight $\beta 1$,4-galactosidase treatment (a minor degalactosylation product co-eluting with $\mathrm{Man}_{4} \mathrm{GlcNAc}_{2}$ at 7.8 g.u.was observed after $>3$ days); after jack bean a-mannosidase treatment resulting in a loss of one hexose and no change in RP-HPLC elution time ( $\mathbf{L}$ and $\mathbf{M}$; co-elution with a bisected trimannosyl-glycan previously discovered in a fut-1;fut-6;fut-8 mutant (14)), the $\mathrm{m} / \mathrm{z} 1151$ product became sensitive to $\beta 1$,4-galactosidase (D-G). *indicates non-glycan impurities; glycans are annotated as $[\mathrm{M}+\mathrm{H}]^{+}$unless otherwise noted, whereby addition of certain glycosidases can lead to a shift to sodiated forms (e.g., panel E) due to the buffer in which the enzymes are supplied. 
RP-HPLC

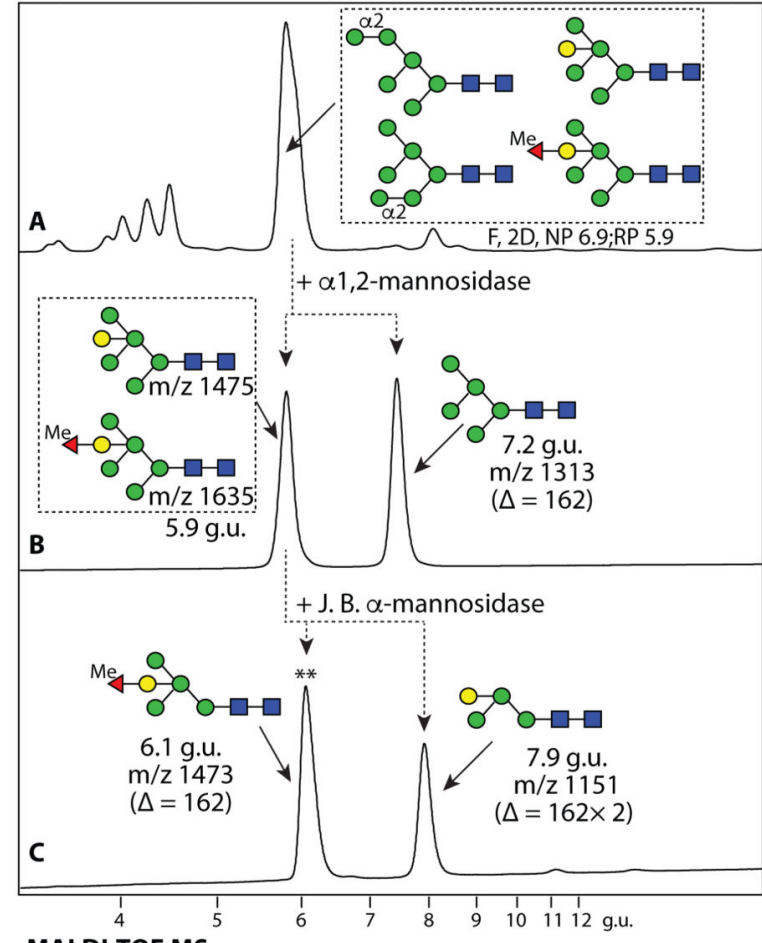

MALDI-TOF MS
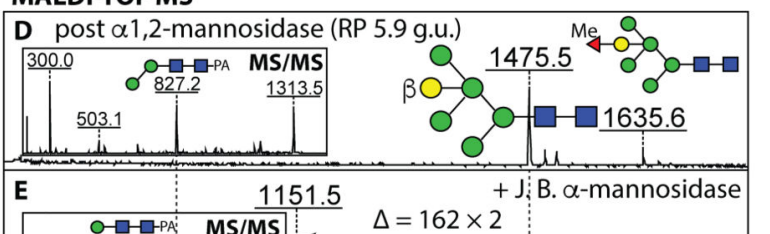

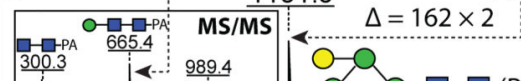

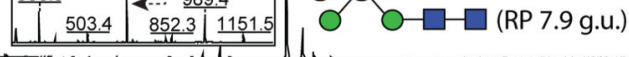

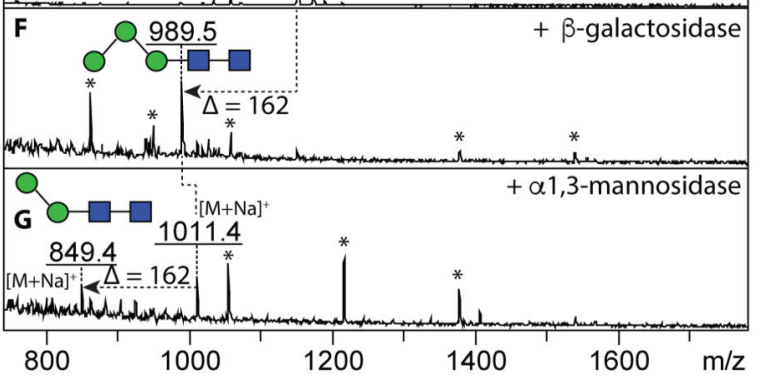

MALDI-TOF MS

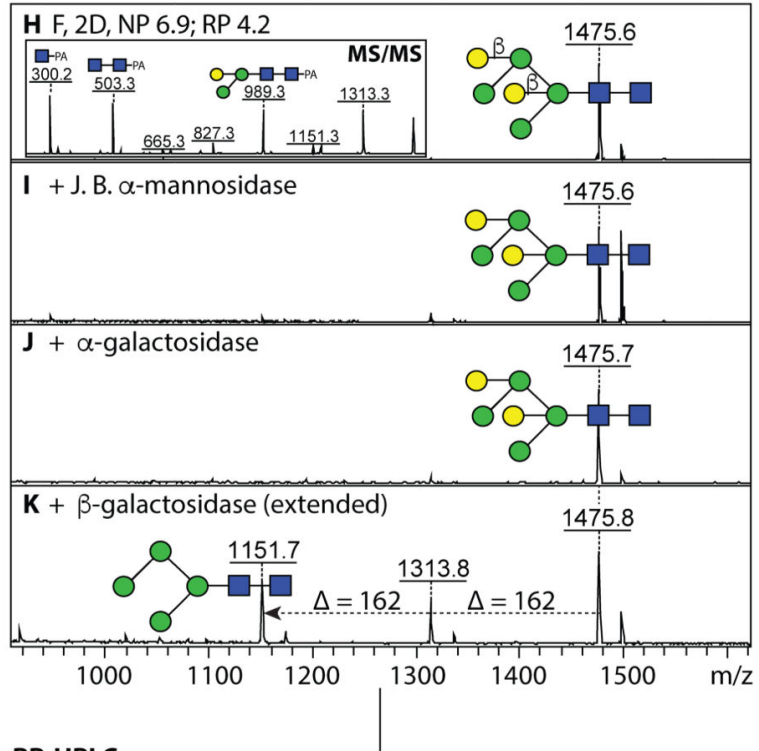

RP-HPLC

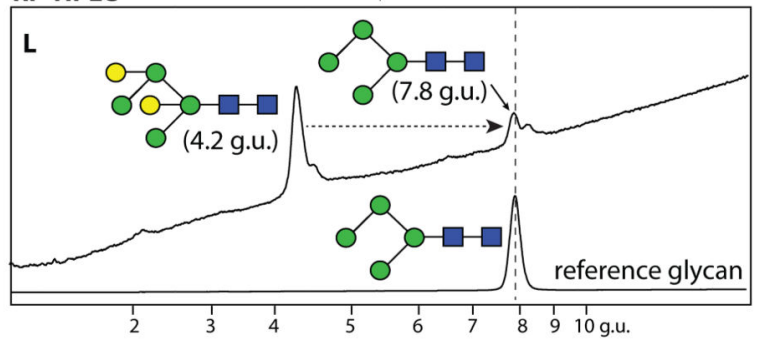

MALDI-TOF MS

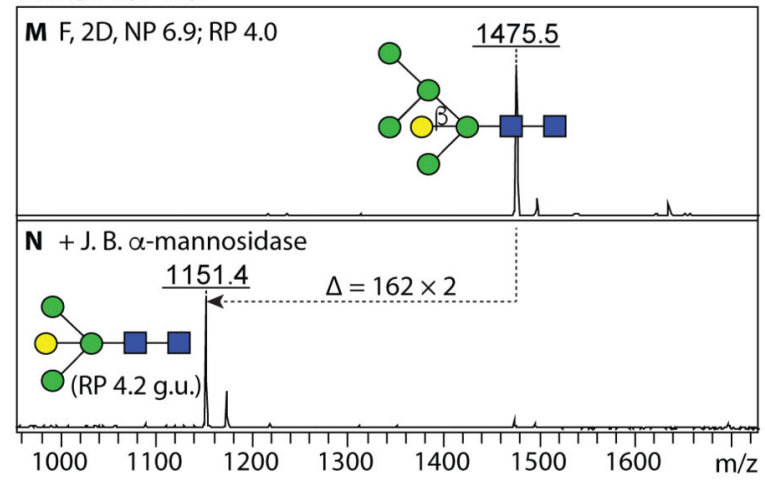

Figure 3. Structural characterisation of mono- or di-galactosylated $\mathrm{Hex}_{6} \mathrm{HexNAc}_{2}$. Multiple $\mathrm{Hex}_{6} \mathrm{HexNAc}_{2}$ isoforms were isolated from the PNGase F released glycan pool. (A-C) One 2D-HPLC fraction (NP 6.9; RP 5.9) contained four structures, including two a 1,2-mannosidase-sensitive oligomannosidic forms (see also Supplementary Figure 4); RPHPLC separated these from the resistant $\mathrm{Hex}_{6} \mathrm{HexNAc}_{2}$ structure, which lost two mannose residues when treated with jack bean a-mannosidase (D-E). The resulting $\mathrm{Hex}_{4} \mathrm{HexNAc}_{2}$ product ( $\mathrm{m} / \mathrm{z} 1151$, eluting at $7.9 \mathrm{~g}$.u.) displayed a strong $\mathrm{m} / \mathrm{z} 665 \mathrm{Y} 3$ fragment (see inset), indicative of the loss of the "lower arm"; (F-G) further treatment with $\beta$-galactosidase and 
a 1,2/3-mannosidase resulted in sequential losses of a galactose and a mannose, indicative of an 'intersected' structure. (H-L) The $\mathrm{Hex}_{6} \mathrm{HexNAc}_{2}$ variant eluting at 4.2 g.u. was only susceptible to prolonged $\beta$-galactosidase digestion (loss of up to two galactose residues), which resulted in a shift to the same RP-HPLC elution time as a regular $\mathrm{Man}_{4} \mathrm{GlcNAc}_{2}$ glycan. (M-N) Another $\mathrm{Hex}_{6} \mathrm{HexNAc}_{2}$ isomer eluting at 4.0 g.u. was considered to be a $\mathrm{Man}_{5} \mathrm{GlcNAc}_{2}$ modified with a bisecting galactose as judged by its sensitivity to jack bean a-mannosidase (concomitant loss of two external mannoses) and the elution property of the truncated product (at RP 4.2 g.u.). * indicates non-glycan impurities; ** contains $\mathrm{m} / \mathrm{z} 1473$ (a mannosidase product of $\mathrm{Hex}_{6} \mathrm{HexNAc}_{2} \mathrm{Fuc}_{1} \mathrm{Me}_{1}$ ) which was sensitive to $\mathrm{HF}$ treatment resulting in a loss of $160 \mathrm{Da}$, indicative of the presence of a methylated fucose residue (data not shown). 
MALDI-TOF MS

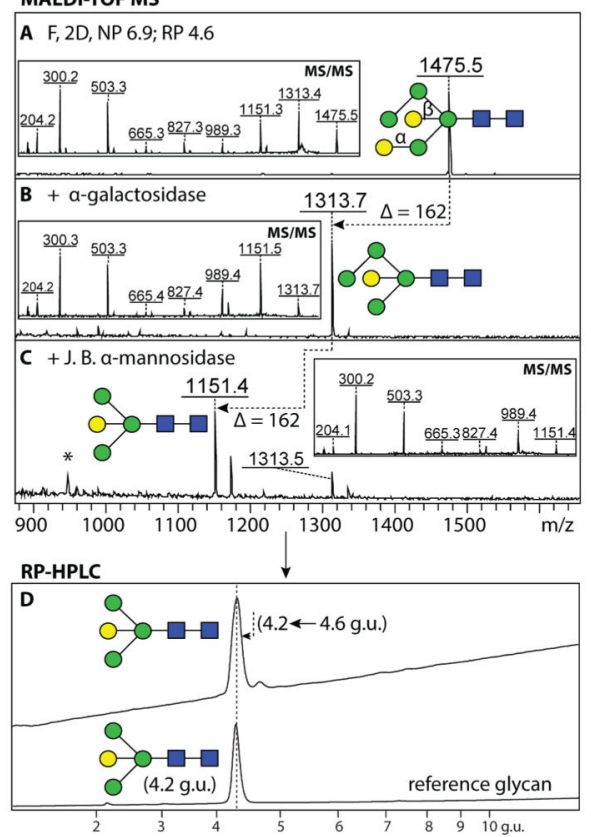

MALDI-TOF MS

I F, 2D, NP 7.7; RP 4.6

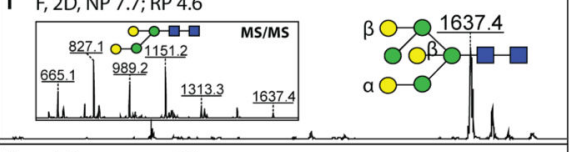

J + J. B. a-mannosidase

(same for 17,2 mannosidase)
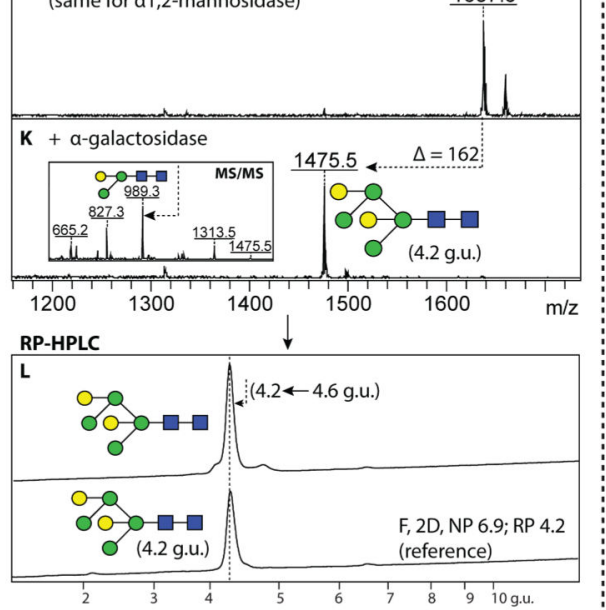

MALDI-TOF MS

E F, 2D, NP 6.9; RP 8.0

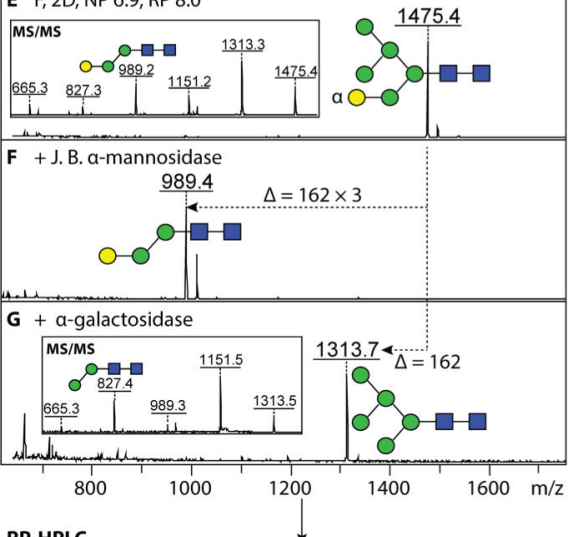

$\mathbf{H}$
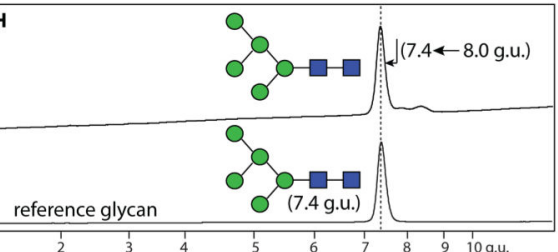

MALDI-TOF MS
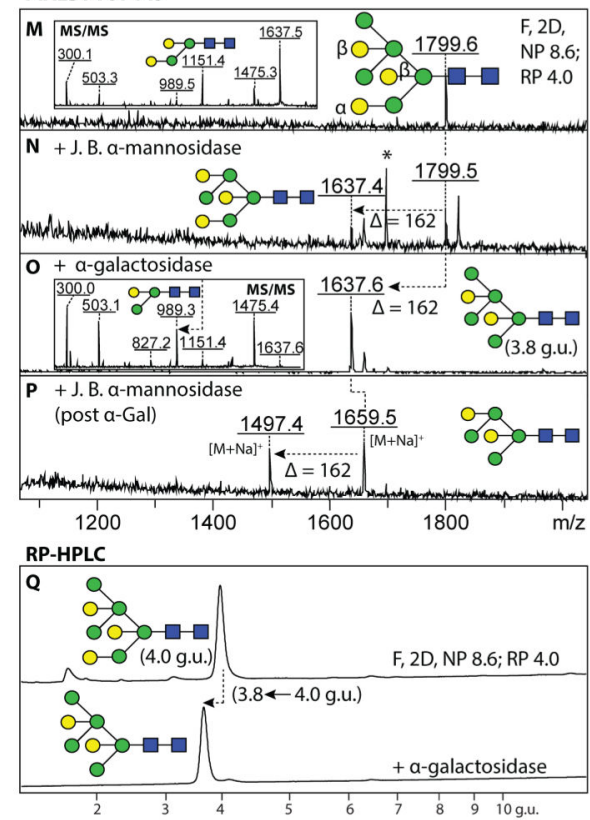

Figure 4. Structural analysis of selected $\mathrm{Hex}_{6-8} \mathrm{HexNAc}_{2}$ glycans containing up to three galactose residues.

(A-D) An isomer of $\mathrm{Hex}_{6} \mathrm{HexNAc}_{2}$ (NP 6.9; RP 4.6) was sequentially digested by agalactosidase and jack bean a-mannosidase, resulting in sequential loss of two hexose residues (see also MS/MS spectra in insets) to yield a product co-eluting with a previously defined bisected $\mathrm{Gal}_{1} \mathrm{Man}_{3} \mathrm{GlcNAc}_{2}$ structure (see Figure 2). (E-H) A late eluting $\mathrm{Hex}_{6} \mathrm{HexNAc}_{2}$ (RP 8.0 g.u.) displayed partial sensitivity to jack bean a-mannosidase and $\mathrm{a}$ galactosidase, as judged by the loss of either three hexose residues or solely one hexose 
residue, respectively (relevant MS/MS spectra are shown as insets); the a-galactosidase product $\mathrm{Hex}_{5} \mathrm{HexNAc}_{2}$ co-eluted at 7.4 g.u. (RP-HPLC) with a PA-labelled Man5 standard. (I-L) A 2D-HPLC isolated $\mathrm{Hex}_{7} \mathrm{HexNAc}_{2}$ isomer (NP 7.7 g.u. and RP 4.6 g.u.; see Supplementary Figure 4) was resistant to jack bean a-mannosidase, but lost one hexose after incubation with coffee bean a-galactosidase resulting in a shift of retention time to 4.2 g.u., thereby co-eluting with a $\mathrm{Gal}_{2} \mathrm{Man}_{4} \mathrm{GlcNAc}_{2}$ structure (see the characterisation in Figure 3). (M-Q) A $\mathrm{Hex}_{8} \mathrm{HexNAc}_{2}$ isomer (NP 8.6; RP 4.0 g.u.) was partially resistant to jack bean amannosidase, but lost one galactose after incubation with coffee bean a-galactosidase and the product was still only partially digestible with jack bean a-mannosidase; HPLC data indicated a shift to slightly-earlier retention time post a-galactosidase treatment. * indicates non-glycan impurities. 


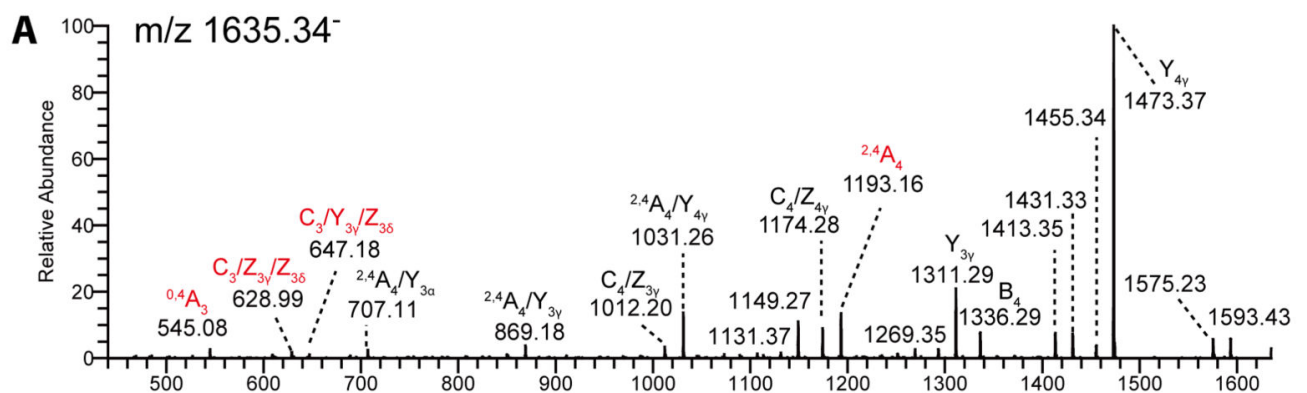

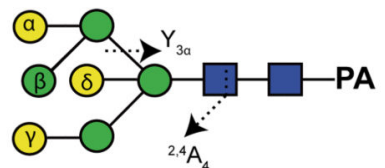

H7N2

(F, 2D, NP 7.7; RP 4.6)

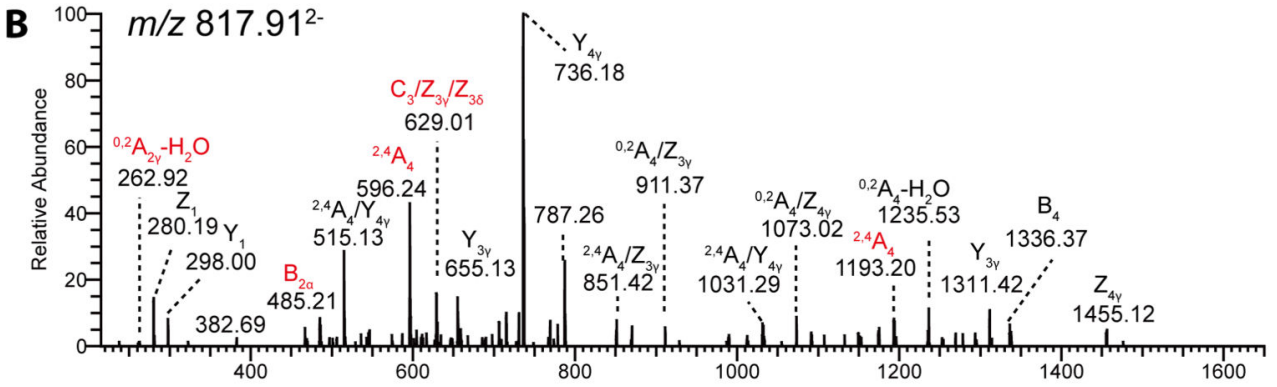

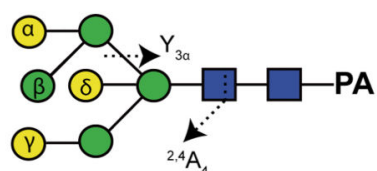

H7N2

(F, 2D, NP 7.7; RP 4.6)
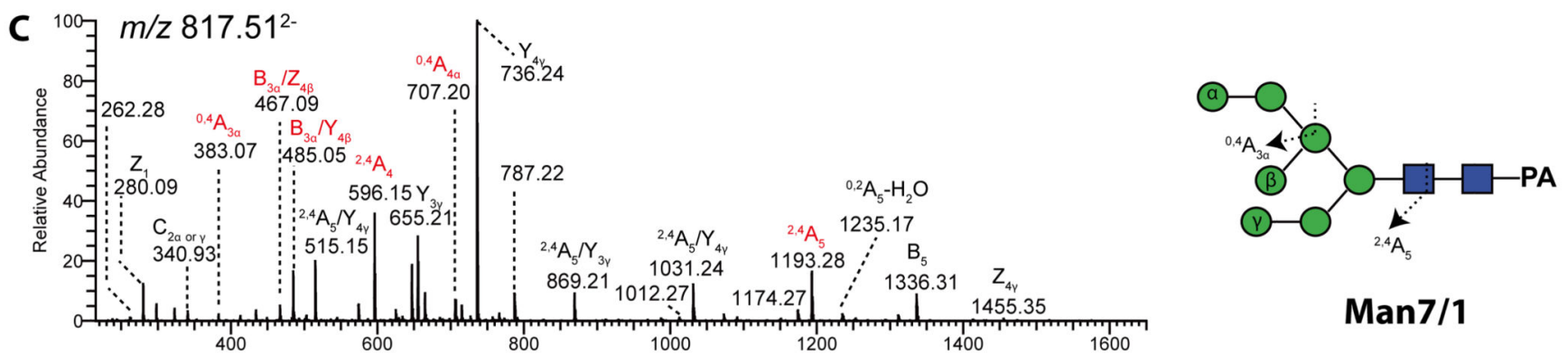

Man7/1
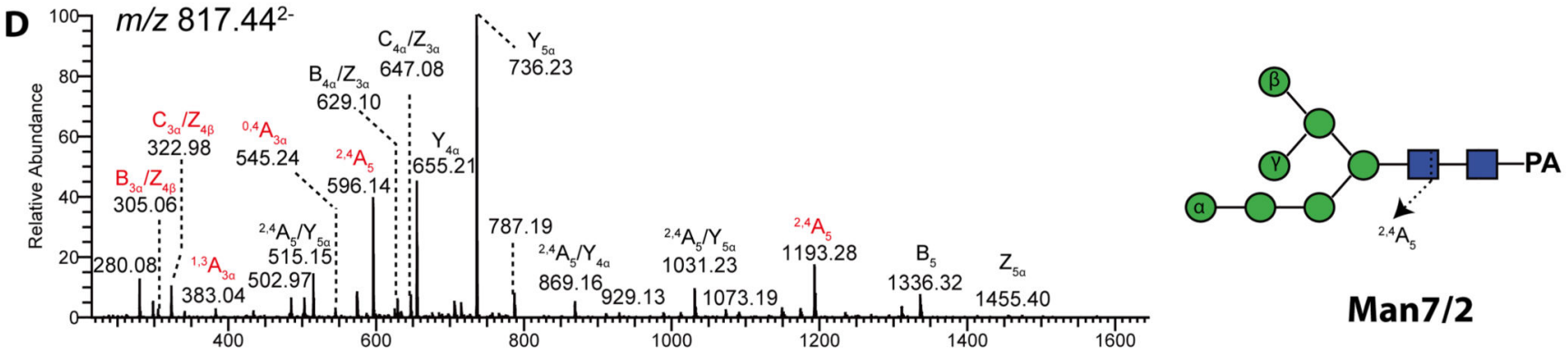

Man7/2

Figure 5. LC-MS ${ }^{2}$ spectra of $\mathrm{Hex}_{7} \mathrm{HexNAc}_{2}$ glycans in negative ion mode.

(A) LC-MS analysis of a 2D-separated $\mathrm{Hex}_{7} \mathrm{HexNAc}_{2}$ structure (4.6 g.u. on RP-HPLC; see Figure 4I-L) yielded, e.g., cross-ring ${ }^{2,4}$ A cleavage ions at $m / z 1193$ and D ions at $\mathrm{m} / z$ $647 / 629$ including the $\beta 4$ Man and its C6 branch as well as ions at $\mathrm{m} / z 545$ resulting from cross-ring ${ }^{0,4} \mathrm{~A}$ cleavage of the $\beta 4 \mathrm{Man}$; taken together the MS/MS indicates there are three Hex residues on the C6 branch of the $\beta 4$ Man. However, the MS/MS spectrum of doubly charged ions at $m / z 817.91$ (B) contrasts with those for typical Man7/1 and M7/2 structures which are the same as those previously observed in Penicillium (C-D; see Ref. (34)). First, the presence of $m / z 263$ indicates that this $\mathrm{Gal}_{3} \mathrm{Man}_{4} \mathrm{GlcNAc}_{2}$ structure has a terminal 1,4linked Hex (B). Second, as compared to classical Man ${ }_{7} \mathrm{GlcNAc}_{2}$ isomers, certain fragmentation ions are missing: i.e., those at $\mathrm{m} / \mathrm{z} 383\left({ }^{0,4} \mathrm{~A}\right.$ cleavage of a6Man $(\mathbf{C})$ or ${ }^{1,3} \mathrm{~A}$ 
cleavage of a 3Man in (D) releasing fragment ions containing linear Hex2 + $59 \mathrm{Da}$ ), $\mathrm{m} / \mathrm{z} 323$ and 305 (secondary D ions in (D)) and $\mathrm{m} / \mathrm{z} 707$ or $\mathrm{m} / \mathrm{z} 545$ (ions diagnostic for non-bisected $\beta 4$ Man or a6Man in $(\mathbf{C})$ and in (D)). Thus, it is concluded that the $\mathrm{Gal}_{3} \mathrm{Man}_{4} \mathrm{GlNNAc}_{2}$ glycan possesses a substituted $\beta 4$ Man with a bisecting Hex ( $\beta \mathrm{Gal})$, a 1,4-linked Hex (aGal) linked to a3Man and two Hex residues on the a6Man; these two Hex residues are neither arranged in a linear manner nor contain a typical C3/C6-disubstituted a6Man. It is likely that one Man residue is linked to the $\mathrm{C} 3$ position of a6Man, while another Hex (second $\beta \mathrm{Gal}$ ) links to the unusual intersecting $\beta 1,4$-substitution of the a6Man. 

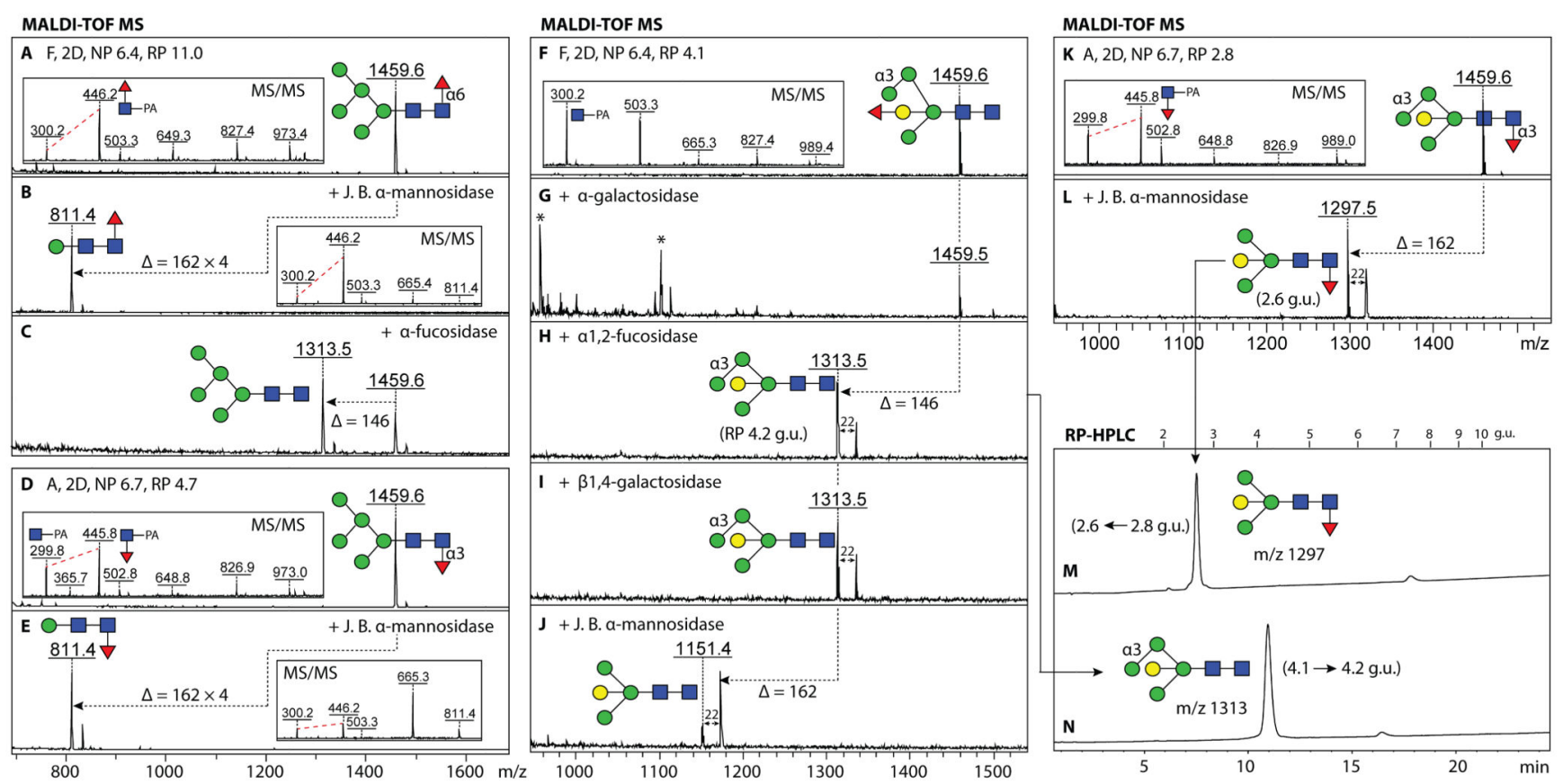

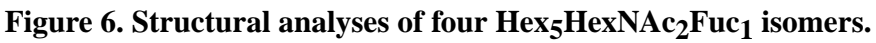

(A-C) A minor isomer corresponded to an core a 1,6-fucosylated form of $\mathrm{Man}_{5} \mathrm{GlcNAc}_{2}$ as judged by its late elution (11.0 g.u.) on RP-HPLC and its sensitivity to jack bean amannosidase (loss of four hexose residues) and to bovine kidney a-fucosidase (loss of one deoxyhexose). (D-E) In the PNGase A released glycan pool, a second isomer displayed a similar sensitivity to a-mannosidase, but its early RP-HPLC elution (at 4.7 g.u.) and sensitivity to hydrofluoric acid treatment (loss of one deoxyhexose, data not shown) indicated it to be core a 1,3-fucosylated. (F-J) An isoform carrying a bisecting Fuca 1,2Gal $\beta 1,4$ disaccharide unit (4.1 g.u.) was confirmed by sequential exo-glycosidase digestions, whereby the a1,2-fucosidase digestion product co-eluted (N) with an already characterised bisected glycan at 4.2 g.u.; jack bean a-mannosidase sensitivity was observed not on the intact glycan (not shown), but only after the fucosidase treatment. (K and L) A further bisected isoform with a 1,3-linked core fucose (2.8 g.u.) lost one residue upon jack bean a-mannosidase digestion, which resulted in a minor alteration in retention time from 2.8 to 2.6 g.u. (M). MS/MS of the four forms of $\mathrm{Hex}_{5} \mathrm{HexNAc}_{2} \mathrm{Fuc}_{1}$ are also shown, whereby in three cases the $\mathrm{m} / z 446 \mathrm{Y} 1$ fragment correlates with core fucosylation; the dashed red lines highlight the varying ratios of the $\mathrm{m} / z 300$ and 446 fragments (insets in A, D, F and $\mathrm{K})$. 

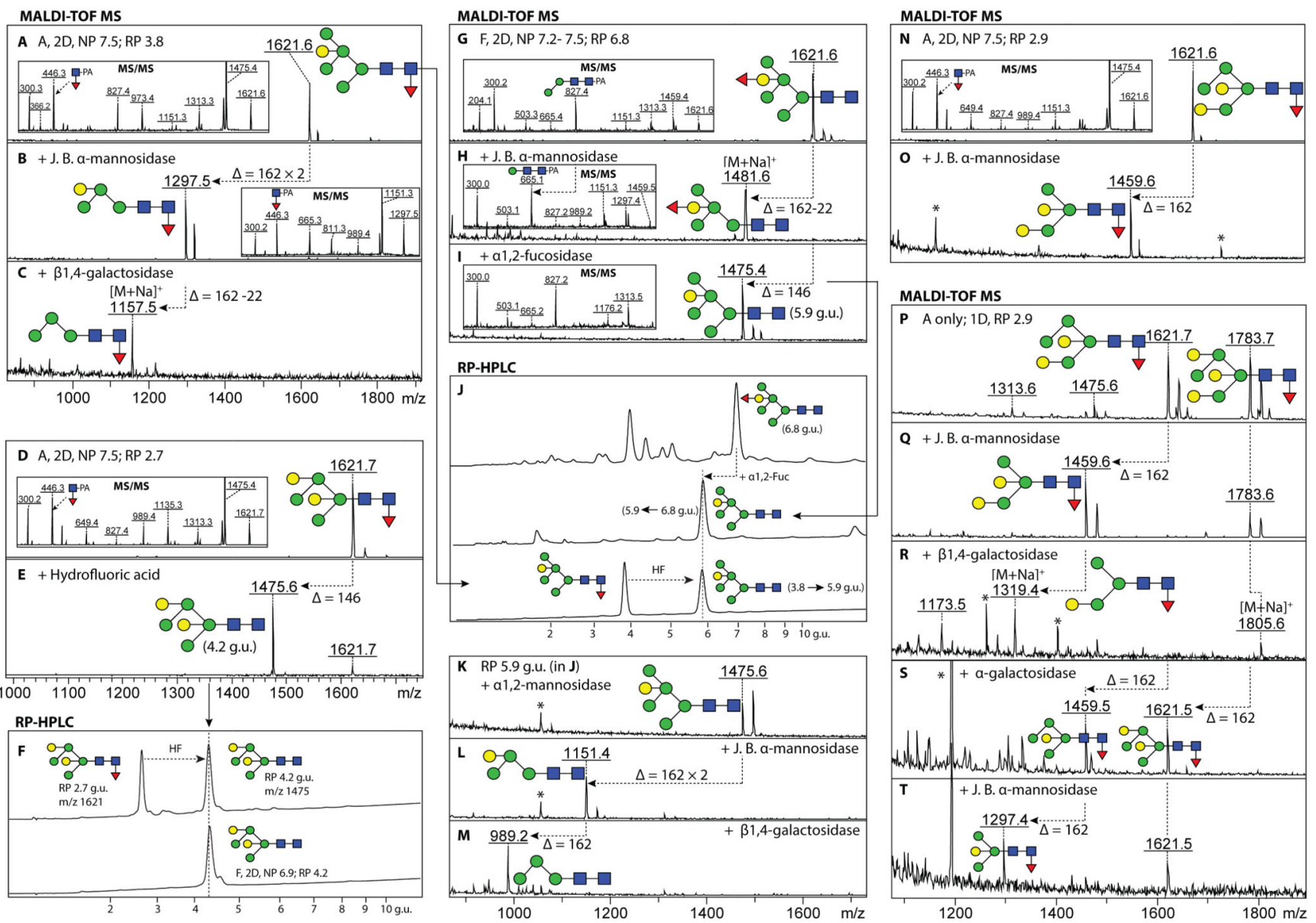

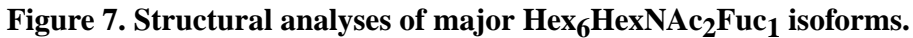

(A-C) One $\mathrm{Hex}_{6} \mathrm{HexNAc}_{2} \mathrm{Fuc}_{1}$ isomer (RP 3.8 g.u.) lost two mannose residues and one galactose upon serial incubation with a-mannosidase and $\beta$-galactosidase. (D-F) The second form of $\mathrm{Hex}_{6} \mathrm{HexNAc}_{2} \mathrm{Fuc}_{1}$ eluting at 2.7 g.u. was susceptible to hydrofluoric acid treatment which resulted in the loss of one fucose and a shift to later retention time (co-elution at 4.2 g.u. with one form of $\mathrm{Hex}_{6} \mathrm{HexNAc}_{2}$ ). (G-I) The third $\mathrm{Hex}_{6} \mathrm{HexNAc}_{2} \mathrm{Fuc}_{1}$ isomer (RP 6.8 g.u.) was sensitive to jack bean a-mannosidase and a 1,2-fucosidase, resulting in loss of one mannose and one fucose; the fucosidase product $(\mathrm{m} / \mathrm{z} 1475)$ eluted at 5.9 g.u. on RP-HPLC $(\mathbf{J})$, thereby co-eluting with the HF product of the $\mathrm{Hex}_{6} \mathrm{HexNAc}_{2} \mathrm{Fuc}_{1}$ isomer depicted in panel A. (K-M) The defucosylated 5.9 g.u. glycan was resistant to a 1,2-mannosidase, but sensitive to serial treatment with jack bean $\alpha$-mannosidase and $\beta$-galactosidase, losing two mannose and one galactose residues. ( $\mathbf{N}$ and $\mathbf{O}$ ) A fourth 2D-HPLC isolated $\mathrm{Hex}_{6} \mathrm{HexNAc}_{2} \mathrm{Fuc}_{1}$ isomer (eluting at RP 2.9 g.u.) lost a single mannose upon jack bean amannosidase treatment. (P) The same isomer co-eluted with a $\mathrm{Hex}_{7} \mathrm{HexNAc}_{2} \mathrm{Fuc}_{1}$ structure in a fraction (2.9 g.u.) solely separated on RP-HPLC from the PNGase A-only released glycome. While the $\mathrm{m} / z 1621$ structure displayed sequential sensitivities to jack bean amannosidase and $\beta$-galactosidase, resulting in conversion of $\mathrm{Hex}_{6} \mathrm{HexNAc}_{2} \mathrm{Fuc}_{1}$ to $\mathrm{Hex}_{4} \mathrm{HexNAc}_{2} \mathrm{Fuc}_{1}$ ( $\mathbf{Q}$ and $\mathbf{R}$ ), both glycans in this fraction lost one galactose upon treatment with a-galactosidase $(\mathbf{S})$; an additional loss of mannose from the smaller product 
could then be released by subsequent a-mannosidase treatment (T). MS/MS spectra of relevant glycans are shown as insets; * indicates non-glycan impurities. For the pattern of mannosidase sensitivity and galactosidase resistance of a methylated form of $\mathrm{Hex}_{6} \mathrm{HexNAc}_{2} \mathrm{Fuc}_{1}$, compatible with a fucose substitution of intersecting galactose rather than mannose, refer to Supplementary Figure 7; note that the sterically hindrance caused by the $\beta$-galactose residues explains the non-removal of some mannose residues (see Supplementary Figure 8). 

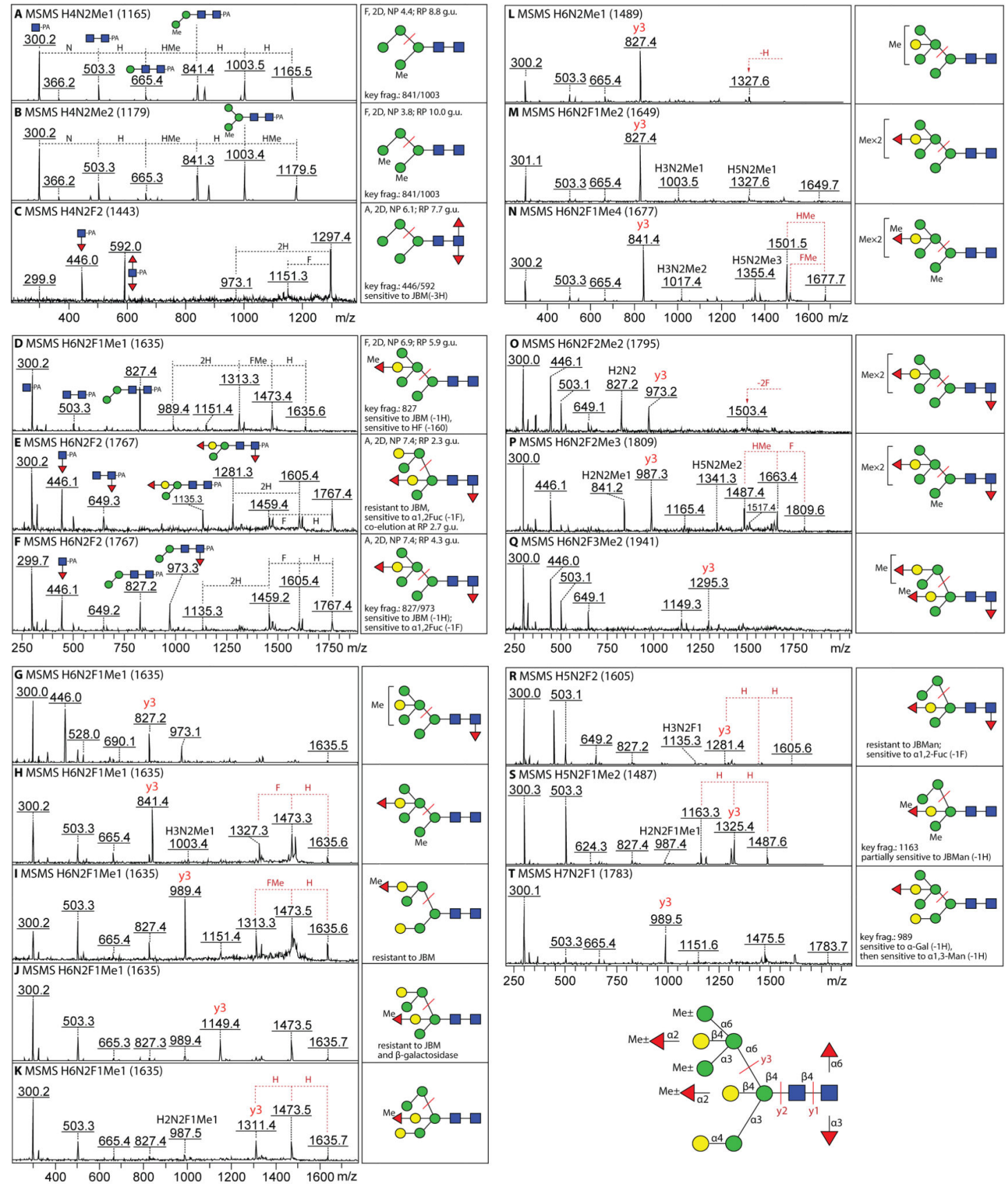

Figure 8. MS/MS spectra of selected methylated and fucosylated glycans.

(A-F) Structures of 2D-HPLC separated $\mathrm{Hex}_{4-5} \mathrm{HexNAc}_{2} \mathrm{Fuc}_{0-2} \mathrm{Me}_{0-2}$ glycans are proposed based on their key fragment ions as well as sensitivities to glycosidase/chemical treatments. A typical cleavage between the core $\beta 1,4-M a n$ and the a1,6-Man branch (upper arm) resulted in diagnostic $\mathrm{Y} 3$ ions, such as $\mathrm{m} / \mathrm{z} 827\left(\mathrm{Hex}_{2} \mathrm{HexNAc}_{2}\right), \mathrm{m} / \mathrm{z} 841$ $\left(\mathrm{Hex}_{2} \mathrm{HexNAc}_{2} \mathrm{Me}_{1}\right), \mathrm{m} / \mathrm{z} 973\left(\mathrm{Hex}_{2} \mathrm{HexNAc}_{2} \mathrm{Fuc}_{1}\right)$ which indicated the location of methylgroup and fucose residues (A, B, D and F). Core fucosylation typically displayed either $\mathrm{m} / \mathrm{z}$ 446 (monofucosylated) or $\mathrm{m} / \mathrm{z} 592$ (difucosylated) Y1 ions as shown in $\mathbf{C , ~} \mathbf{E}$ and $\mathbf{F}$; whereas 
the presence of fucose on the intersecting and bisecting positions (D-F) was deducted by its sensitivity to hydrofluoric acid (HF, loss of 160 Da corresponding to a methyl-Fuc) or an a 1,2-specific fucosidase (loss of 146 corresponding to Fuc) as well as mannosidase sensitivity and galactosidase resistance (see Supplementary Figure 7). (G-T) Further examples of mono-, di- and trifucosylated $\mathrm{N}$-glycans based on $\mathrm{Hex}_{5-7} \mathrm{HexNAc}_{2}$ with varying numbers of methyl groups are annotated with the diagnostic Y3 fragment ions; in the case of glycans fucosylated on the bisecting galactose, Y3 ions such as $m / z 1149$ or 1281 are observed, while additional methylation and a-galactosylation correlates with fragments at $\mathrm{m} / \mathrm{z} 1163$ and 1311. Brackets indicate uncertainty regarding methylation positions; Y1, Y2 and Y3 cleavages are shown on the generalised structure. 